\title{
Temporal and Spatial Differentiation in Urban Resilience and Its Influencing Factors in Henan Province
}

\author{
Lu Liu ${ }^{1}$, Yun Luo ${ }^{1}$, Jingjing Pei ${ }^{1, *}$, Huiquan Wang ${ }^{2}$, Jixia $\mathrm{Li}^{3}$ and Ying $\mathrm{Li}^{1}$ \\ 1 School of Engineering and Technology, China University of Geosciences, Beijing 100083, China; \\ liulwhq@cugb.edu.cn (L.L.); luoyun@cugb.edu.cn (Y.L.); lucineliying@cugb.edu.cn (Y.L.) \\ 2 School of Politics and Public Administration, China University of Political Science and Law, \\ Beijing 100088, China; whqlustrive@cupl.edu.cn \\ 3 School of Government Management, Beijing Normal University, Beijing 100875, China; \\ 202131260023@mail.bnu.edu.cn \\ * Correspondence: Peijj@cugb.edu.cn; Tel.: +86-136-7122-7018
}

Citation: Liu, L.; Luo, Y.; Pei, J.; Wang, H.; Li, J.; Li, Y. Temporal and Spatial Differentiation in Urban Resilience and Its Influencing Factors in Henan Province. Sustainability 2021, 13, 12460. https://doi.org/ $10.3390 /$ su132212460

Academic Editors: Bharat Dahiya and Jonathan Parkinson

Received: 4 October 2021

Accepted: 8 November 2021

Published: 11 November 2021

Publisher's Note: MDPI stays neutral with regard to jurisdictional claims in published maps and institutional affiliations.

Copyright: (c) 2021 by the authors. Licensee MDPI, Basel, Switzerland. This article is an open access article distributed under the terms and conditions of the Creative Commons Attribution (CC BY) license (https:// creativecommons.org/licenses/by/ $4.0 /)$.
Abstract: Building resilient cities is playing an increasingly important role in enhancing urban safety and promoting sustainable urban development. However, few scholars pay attention to urban resilience in inland provinces. Choosing Henan Province, as it is a typical representative of China's major inland economic provinces, has practical guiding significance. This study aims to provide a systematic indicator system and evaluation tool to measure the cuity's resilience level. Therefore, based on a multidimensional perspective, this paper dissects the urban resilience spatial and temporal evolution characteristics of 18 Henan Province cities with the entropy method, Thiel index, and ESDA (Exploratory Spatial Data Analysis) and explores influencing factors with a spatial econometric model. The main results are as follows: (1) the overall resilience in Henan Province continuously grows, and the resilience level of the Zhengzhou metropolitan area is the highest. In the urban resilience subsystem, economic and social resilience notably drive urban resilience improvement in Henan Province. (2) The spatial difference of urban resilience has been significantly reduced, but the inner metropolitan area presents the characteristics of "core-periphery". Urban resilience presents a positive spatial correlation, and local spatial agglomeration is relatively stable. (3) Under the state of spatial interaction, urbanization rate, administrative, innovation, market, and industrial structure factors all have significant direct effects and spatial spillover effects on overall resilience, but openness exerts downward pressure on local resilience. (4) On this basis, strategies have been proposed to continuously promote the development of new urbanization, improve the regional coordinated development mechanism, increase market activity, optimize the environment for scientific and educational innovation, and promote the optimization and upgrading of industrial structure. The approach taken in this research may also be useful for developing urban resilience assessment tools in other central plains cities as well as in other cities in the interior of the world with similar conditions.

Keywords: urban resilience; temporal and spatial differentiation; spatial analysis; Henan Province

\section{Introduction}

The sustainable and healthy development of cities is an important manifestation of economic development and social progress. With the rapid development of urbanization, cities are facing increasingly serious uncertainty problems. The United Nations predicted that by the end of 2050, more than $66 \%$ of the population will live in cities [1]. The World Bank assessed the risk status of 633 large cities worldwide in 2013 and found that 450 countries were exposed to the risk of at least one disaster [2]. The 2018 Lloyd Urban Risk Index Report noted that 279 cities worldwide (including 36 Chinese cities) faced the risk of 22 threats, revealing that most natural disaster risks accounted for $63.4 \%$ of the total 
risk-related gross domestic product (GDP), while human risks, such as network crime, interstate conflicts, or market collapse, accounted for $36.6 \%$ of the total risk-related GDP [3].

As the centers of political, economic, and cultural activities, cities provide a large number of employment opportunities. They are characterized by concentrated populations, dense buildings, and interconnected infrastructures, which make them function properly and more livable, but also increase their vulnerability to disasters. Urban systems are constantly exposed to disturbances and damage stemming from natural and man-made factors highly prevalent in modern society, such as extreme climate disasters, geological disasters, major infectious diseases, terrorist attacks, information technology risks, population aging, and backward infrastructure. The COVID-19 outbreak tremendously impacted the health of cities worldwide, exposing many of the problems and shortcomings of cities in terms of managing risk and further highlighting the importance of enhancing the resilience of urban systems. In the face of the growing security needs of people and the increasing uncertainties in cities, scientists, politicians, and urban managers have carried out relevant research and adopted emergency countermeasures, and building resilient cities is the most important aspect.

This paper analyzes the spatial pattern of urban resilience and its influencing factors in a specific region by using the entropy method, Thiel index, and ESDA from the level of endogenous development capacity of cities and their optimization of the spatial pattern of regional development. Given the current situation of Henan Province, wherein "the overall resilience is continuously growing and evolving, the ecological resilience and engineering resilience have shortcomings, and the local effect and spatial spillover effect of openness on urban resilience are negative", we propose measures to continuously promote the development of new urbanization; improve the mechanism of regional collaborative development; enhance market activity; optimize the environment of science, education, and innovation; and promote the optimization and upgrading of industrial structure to provide experience and reference for the construction of resilient cities.

\section{Resilience}

Linguistically speaking, the word resilience originates from the Latin word "resil-io", which means to return to its original state. The concept of resilience was first introduced in 1973 by C. S. Holling, a professor of ecology at the University of Florida; in his landmark book Resilience and Stability of Ecological Systems, he proposed the concept of "ecosystem resilience" [4], which means "The persistence of natural systems in response to changes in ecosystems caused by natural or man-made causes". In the 1980s, the application of resilience theory was extended to the field of disaster management, leading disaster scholars to shift their focus from vulnerability to resilience. In the 1980s, the application of resilience theory was extended to the field of disaster management, leading scholars in the field of disasters to shift their focus from vulnerability to resilience. In 1996, C. S. Holling further identified the difference between "ecological resilience" and the traditional concept of "engineering resilience" in the book Engineering Resilience Versus Ecological Resilience, and pointed out that the two different definitions of resilience stemmed from the differences in the concepts of "stability" and "equilibrium". At the end of the 1990s, scholars gradually expanded the study of resilience from natural ecology to human ecology. The city as a major component and activity subject of human ecology, the idea of resilience has been naturally applied to urban research, laying the foundation for the formation of resilient city theory.

The development of resilience theory has undergone three conceptual changes: engineering resilience [5], ecological resilience [6], and socio-ecological resilience [7], each of which has enriched the conceptual content of resilience. Resilient cities were first proposed by the International Council in 2002, and they were introduced into urban disaster research, which promoted a research wave in the field of urban resilience. The Second World Conference on Disaster Reduction in 2005 included resilience in the policy area of sustainable urban development [8]. Subsequently, international research organizations 
and scholars conducted extensive and in-depth studies on the multisectoral, regional, and comprehensive characteristics of urban resilience, such as the Global 100 Resilient Cities project launched by the Rockefeller Foundation in 2013, which aims to improve the comprehensive resilience of cities by addressing uncertainties in social, economic, institutional, and infrastructure areas [9]. In 2016, the Third United Nations Conference on Housing and Sustainable Urban Development (UNCHSUD) released the New Urban Agenda, which advocated the ecology and resilience of cities as core agenda elements, setting a new global standard for the sustainable development of resilient cities [10]. In recent years, China has successfully established administrative departments and research centers, such as the Ministry of Emergency Management and the Resilient City Research Center of Zhejiang University. In the newest round of city master plans of Beijing and Shanghai, relevant expressions, such as strengthening the ability of a city to cope with disasters and improving the city resilience, have been included. In addition, the concept of resilient cities was first put forward in the Proposal of the Central Committee of the Communist Party of China on Formulating the Fourteenth Five-Year Plan for National Economic and Social Development and Vision Goals for the Year 2035. Therefore, urban resilience has become a hot research topic in current international urban planning, sustainable urban development, and urban risk prevention. Through combing and summarizing the domestic and foreign resilience research literature, it is found that from the existing research, the related research on urban resilience mainly focuses on the three aspects of connotation characteristics, theoretical deduction, and indicator system.

In terms of connotation features: due to the unique perceptions of the concept of the resilience of different disciplines or institutions, the concept of urban resilience also varies: according to disaster science researchers [11], e.g., Jha et al. [12], Godschalk et al. [13], and Bozza et al. [14], from the perspective of disaster science that urban resilience is a system, a given community or society can effectively resist, absorb, and bear the impact of disasters, and the main characteristics, structure, and key functions can be restored. Shen et al. [15], Meerow et al. [16], Shao et al. [17], and UN-Habitat [18] proposed that, from the perspective of urban planning, urban resilience refers to the ability to realize the normal operation of public safety, social order, and economic construction through reasonable preparation, buffering, and uncertainty disturbance mitigation. In terms of intrinsic dimensions [19], existing studies on urban resilience have covered multiple dimensions, such as economic [20,21], ecological [22,23], engineering [24,25], and social dimensions [26]. From the perspective of the evolution of resilient cities, due to the complexity, openness, and comprehensiveness of the urban system [27], the construction of urban resilience involves all aspects of a given city, which is a dynamic and complex urban network involving interactions between human and environmental systems. Patricia Romero-Lankao et al. focus on the influences that enhance urban resilience from the perspective of urban actors and how different definitions of these concepts intersect, complement, or contradict each other [28].

In terms of theoretical deduction: at present, the research perspectives and themes of the theoretical framework of urban resilience are diversified and scattered. Relevant research can mainly be summarized from three perspectives, namely, disaster response, urban governance, and complex adaptive systems, as represented by Cutter [29], etc., who proposed the local disaster resilience framework (disaster resilience of a place (DROP)), thereby paying attention to the city when managing the risk of resource availability and redundancy and representative facilities and characteristics. Ayyoob Sharifi et al. studied nine blocks representing three different urban forms (traditional, semi-planned, and planned) in Iran and analyzed the resilience of different blocks in response to three stress sources (earthquakes, extreme heat, and floods) [30]. The urban governance framework focuses on addressing the connection and coordination between urban emergency management and urban planning. Many scholars and international organizations have proposed frameworks such as the resilient city planning framework (RCPF) [31] and city resilience index (CRI) [32], aiming at the current situation and system of urban resilience to improve 
urban resilience through planning, design, and management. Grazia Brunetta et al. [33] proposed that measuring urban resilience mainly faces both conceptual and methodological barriers, and Stella Manika et al. [34] argued that the optimal location of enterprises is conducive to improving urban resilience and economic strength. The complex adaptive system framework emphasizes that urban risk prevention and control strategies are proposed in stages, and the core is based on feedback-loop system theory, such as the human-environment system (HES) [35] and resilience, adaptation, and transformation assessment (RATA) frameworks [36]. Nyström et al. [35] believed that the system's structure, functions, and interrelationships change over time. They proposed a framework for human-environment coupled system sustainability (the HES framework), which linked human-environment systems with resilience research and enhanced the resilience of urban systems through connectivity, dynamic mechanisms, and mutual feedback.

In terms of indicator systems: the evaluation index systems of urban resilience have generally been constructed from three aspects through empirical research, including the basic components and characteristics of urban resilience and the sequence of the stages and processes of urban resilience. In terms of the basic components of urban resilience, Sun et al. [37], Zhang et al. [38], and Songj et al. [39] constructed an index system based on the economy, society, ecology, and municipal infrastructure via geographic-informationsystem (GIS)-based spatial analysis, the superposition function method, analytic hierarchy process (AHP), and factor analysis method. The urban resilience of the Yangtze River Delta and Guangzhou, China, was evaluated. Nadro et al. [40] proposed a composite index construction method to evaluate the resilience of 50 cities in Spain from four aspects: social, economic, ecological, and organizational aspects. In the index evaluation system based on the characteristics of urban resilience, Heeksr et al. [41] considered the fairness of resilience evaluation as the key point and proposed to evaluate whether the system could provide equal rights and opportunities of resource utilization with two categories of index systems: functional and enabling characteristics. Li Tongyue [42] applied the robustness, redundancy, resourcefulness, and rapidity (4R) framework of Bruno to construct an evaluation system for the response of a city to rain and flood damage. Parsons and Morley [43] evaluated the characteristics of coping ability and adaptability, corresponding to the different stages at which resilience plays a role. Based on the process sequence of the various resilience stages as the core, according to the disaster-prevention stage, disaster-absorption stage, and system-recovery stage, Chen Changkun et al. [44] established an evaluation system of urban resilience within the context of rain and flood disasters, starting from three attributes of urban resistance, resilience, and adaptability.Bruno et al. [45] reported that the resiliency state of urban communities after an earthquake could be represented by the change in infrastructure functionality over time.

In summary, current scholars have achieved fruitful results in resilient cities. However, due to the late start of resilient cities, existing researchers tend to explore the concepts and theories of urban resilience. There are few comprehensive evaluations, the evaluation methods are not systematic enough, and there are fewer discussions on the factors affecting resilient cities. In terms of evaluation objects, most scholars have conducted more resilient city evaluations on cities and regions with high economic levels, and relatively little attention has been paid to the research on resilient cities in inland provinces. Therefore, compared to the above existing research, the main contributions of this paper include the following: (1) this study is the first to comprehensively and systematically consider the spatial and temporal distributions of urban resilience characteristics and their influencing factors in Henan Province, China. (2) In terms of research methods, the combination of the improved entropy method with the addition of time variables and the spatial Durbin model (SDM) constitutes a major innovation in current urban resilience research techniques. (3) In terms of the research depth, many scholars have focused on comprehensive urban resilience evaluation or the analysis of spatial-temporal evolution characteristics. In this paper, the spatial pattern of urban resilience in a specific region and its influencing factors are analyzed from the perspective of the urban endogenous development capacity and 
optimization of the spatial pattern of overall regional development. (4) In terms of research objects, Henan Province, as a major province in China's inland economy and the core province of China's strategy to revitalize the Central Plains, is a typical representative of China's inland cities. The research on the quality development of its new urbanization and the improvement of urban resilience level has certain typicality and reference value. Given these considerations, this paper adopts 18 cities in Henan Province from 2009 to 2018 as the research object, and the entropy method, Theil index, and exploratory spatial data analysis (ESDA) are employed to evaluate and analyze regional differentiation patterns in space and time. Moreover, the influencing factors of the resilience of Henan Province cities are explored through the SDM to strengthen their capacity to mitigate disasters and enhance the resilience of cities in the Central Plains of China. The analysis and findings of this study have important methodological significance for applying the resilient city theory in practice.

\section{Method and Data}

\subsection{Methodology}

\subsubsection{Entropy Weight Method}

Entropy is a physical concept in thermodynamics and was introduced into information theory by Shen Nong, the father of information theory, and entropy has been widely applied in many fields. According to the characteristics of entropy, the entropy method can be used to judge the randomness and disorder of an event, as well as the degree of dispersion of a certain index. If the degree of dispersion of the index is greater, the influence of the index on the comprehensive evaluation is greater. Compared to the subjective weighting evaluation method, such as the AHP and expert-scoring method, the entropy value method can effectively avoid human interference, thereby objectively and accurately evaluating the research object [46]. To realize comparison between different years, this paper improves the traditional entropy method via the addition of time variables to ensure more comprehensive and accurate evaluation of the research object. The specific steps are as follows:

(1) The original matrix is constructed by selecting $a$ years, $n$ cities, and $m$ indicators, where $x_{a i j}$ is the value of the $j$-th indicator of city $i$ in the $a$-th year $(i=1,2 \ldots n ; j=1,2 \ldots m)$.

(2) The index data are standardized to unify data of different dimensions and orders of magnitude.

Positive indicators: $Y_{i j}=\frac{x_{i j}-\min \left(x_{i}\right)}{\max \left(x_{j}\right)-\min \left(x_{j}\right)}$

Negative indicators:

$$
Y_{i j}=\frac{\max \left(x_{j}\right)-x_{i j}}{\max \left(x_{j}\right)-\min \left(x_{j}\right)}
$$

In Equation (1), $Y_{i j}$ is the standardized index value, $x_{i j}$ is the original data of the $j$-th index of the $i$-th city, and $\max \left(x_{j}\right)$ and $\min \left(x_{j}\right)$ are the maximum and minimum values, respectively, of the $j$-th index.

(3) The index weight is calculated. The proportion of the $i$-th city in the $j$-th index is determined as follows:

$$
P_{i j}=\frac{x_{i j}}{\sum_{i=1}^{n} x_{i j}}(i=1,2, \ldots, n ; j=1,2, \ldots, m)
$$

(4) The information entropy value of the $j$-th index $e_{j}$ is obtained as:

$$
e_{j}=-k \sum_{i=1}^{n} p_{i j} \ln \left(P_{i j}\right), \text { fork }>0, k=\frac{1}{\ln (n)}, \text { and } e_{i} \geq 0
$$

(5) The difference coefficient of the $j$-th index is calculated as:

$$
g_{j}=1-e_{j}
$$


(6) The index weight value $w_{i}$ is computed as:

$$
w_{j}=\frac{g_{j}}{\sum_{j=1}^{m} g_{j}}(j=1,2, \ldots, m)
$$

(7) The comprehensive score $S_{j}$ is calculated as:

$$
S_{j}=\sum_{j=1}^{m} w_{j} \cdot P_{i j} \quad(j=1,2, \ldots, m)
$$

\subsubsection{Theil Index Model}

The Theil index is a special form of the generalized entropy (GE), which was originally adopted by Theil to measure and calculate income differences between countries [47] and has since been widely applied in regional comparisons of different dimensions. The Theil index is mainly used to measure the level of regional differences. Compared with the Gini coefficient, the index has the advantage of being able to decompose regional differences and more clearly the sources of regional differences. The index decomposes overall regional differences into intragroup and intergroup differences and more intuitively reveals the variation trend and range of regional differences and the importance and contribution rates of these two differences to the overall differences. In this paper, the Bourguignon, Cowell, and Shorrocks Theil Index (TL) and its corresponding decomposition method were employed to describe the spatial disequilibrium characteristics of urban resilience in Henan Province. The overall Theil index of the urban resilience difference can be expressed as:

$$
T=\frac{1}{n} \sum_{i=1}^{n} \frac{y_{i}}{\bar{y}} \log \left(\frac{y_{i}}{\bar{y}}\right)
$$

Based on measurement of the overall Theil index of regional resilience differences, these differences are decomposed into intraregional intragroup and interregional differences, as expressed in Equations (8) and (9), respectively:

$$
\begin{gathered}
T_{w}=\sum_{k=1}^{m}\left(\frac{n_{k}}{n} \frac{\overline{y_{k}}}{\bar{y}}\right) T L_{k} \\
T_{b}=\sum_{k=1}^{m} \frac{n_{k}}{n}\left(\frac{\overline{y_{k}}}{\bar{y}}\right) \log \left(\frac{\overline{y_{k}}}{\bar{y}}\right)
\end{gathered}
$$

In the above equation, $T$ is the total Theil index, $y_{i}$ is the resilience level of the $i$-th city, $\bar{y}$ is the variable average value of all cities, $n$ is the number of cities, $m$ is the number of regional cities, $n_{k}$ is the number of cities in the $k$ region, and $T_{w}$ and $T_{b}$ denote the intraregional and interregional differences, respectively, in the Theil index. In addition, $T_{w} / T$ is considered to represent the contribution rate of the intraregional differences to the overall regional differences. Similarly, $T_{b} / T$ is determined to represent the contribution rate of the interregional differences to the overall regional differences.

\subsubsection{Exploratory Spatial Data Analysis}

Exploratory Spatial Data Analysis(ESDA) refers to the combination of maps, charts, graphs, and other visualization techniques with spatial statistics theory without any prior judgments or assumptions on the data to diagnose whether the data results have relevant characteristics to reveal the spatial interaction mechanism among research objects. Global and local spatial autocorrelation aspects constitute comprehensive spatial autocorrelation analysis. That is, it is used to test whether a phenomenon in geographic space and the attribute values of its neighboring units are significantly related or present a certain spatial distribution pattern [48].

(1) Global spatial autocorrelation 
The global spatial autocorrelation can describe whether the urban resilience level exhibits agglomeration or diffusion distribution in the overall space, which can be realized by calculating the global Moran index. The global Moran index can be defined as follows:

$$
I=\frac{\sum_{i=1}^{n} \sum_{j \neq i}^{n} W_{i j}\left(x_{i}-\bar{x}\right)}{S^{2} \sum_{i=1}^{n} \sum_{j=1}^{n} W_{i j} x_{i} x_{j} / \sum_{i=1}^{n} \sum_{j=1}^{n} x_{i} x_{j}}
$$

where $n$ is the number of cities, $x_{i}$ and $x_{j}$ denote the variable values of the $i$-th and $j$-th cities, respectively, and $w_{x j}$ is the spatial weight matrix. Moreover, Moran's $I \in(-1,1)$. For Moran's $I>0$, the spatial agglomeration characteristics of the urban resilience level in Henan Province are obvious. When Moran's $I=0$ or approaches 0 , the spatial correlation of the urban resilience level in Henan Province is not relevant, or the correlation characteristics are weak, respectively. Moran's $I<0$ indicates that the urban resilience level in Henan Province exhibits a negative spatial correlation. The smaller the I value is, the stronger the spatial differentiation characteristics.

(2) Local spatial autocorrelation

To compensate for the shortcomings of global autocorrelation analysis and consider the complexity of spatial overflow, Anselin (1995) first proposed local spatial autocorrelation analysis or the local indicators of spatial association (LISA) method to analyze the local characteristics of the spatial association [49]. The local Moran index can be defined as follows:

$$
I_{i}=\frac{x_{i}-\bar{x}}{S} \sum_{j=1}^{n} \overline{W_{i j}}\left(x_{i}-\bar{x}\right)
$$

If the $I_{i}$ value is positive and passes the significance test, this indicates spatial agglomeration of regional units with similar values (high-high (HH) or low-low (LL)). If the $I_{i}$ value is negative and passes the significance test, this indicates spatial agglomeration of regional units with nonsimilar values (high-low or low-high).

\subsubsection{Spatial Measurement Model}

Spatial econometrics was a branch of econometrics that appeared in the middle and late twentieth century. Spatial econometric models mainly consider the spatial effect of an economic phenomenon or an attribute value with the same phenomenon or attribute value on the neighboring spatial units and carry out a series of model settings and testing of econometric modeling methods [50]. Spatial econometrics assumes that the value of a geoeconomic phenomenon or attribute of a spatial unit in one region is correlated with the same phenomenon or attribute of a spatial unit in a neighboring region. This theory of spatial correlation moves away from the traditional assumptions of classical econometrics. This approach improves the general linear regression model (ordinary least squares (OLS)) by considering the spatial correlation between independent and dependent variables, thus resulting in more precise regression coefficients. There are three types of spatial econometric models: the spatial lag model (SLM), spatial error model (SEM), and SDM. The SLM indicates that the explanatory variables of a given spatial cell are influenced by the explanatory variables of neighboring spatial cells. The SEM indicates the extent to which the influence of neighboring spatial units on the error of a variable affects observations in the region. The SDM combines the characteristics of the SEM and SLM. The panel model expressions are as follows:

$$
\begin{gathered}
y_{i t}=\delta \sum_{j=1}^{N} W_{i j} y_{j t}+X_{i t} \beta+\mu_{i}+\varepsilon_{i t} \varepsilon_{i t} \sim \mathrm{N}\left(0, \sigma^{2} \mathrm{In}\right) \\
y_{i t}=X_{i t} \beta+\mu_{i}+\varphi_{i t}, \varphi_{i t}=\lambda \sum_{j=1}^{N} W_{i j} \varphi_{i t}+\varepsilon_{i t}
\end{gathered}
$$




$$
y_{i t}=\delta \sum_{j=1}^{N} W_{i j} y_{j t}+X_{i t} \beta+\sum_{j=1}^{N} W_{i j} X_{j t} \gamma+\mu_{i}+\varepsilon_{i t}
$$

In the above expressions, $i$ and $t$ are the cross-sectional and temporal dimensions, respectively; $\delta$ is the spatial lag autocorrelation coefficient, which measures the influence of the observations of neighboring units on the observations of the considered spatial unit; $\varphi_{i t}$ is the spatial error term; $\lambda$ is the spatial error coefficient, which measures the influence of the error term of neighboring spatial units on the error term of the considered spatial unit; $N$ is the number of spatial units; and $W$ is the spatial weight matrix. $\lambda$ and $\beta$ denote the unknown coefficients, and the hypothesis test of $\mathrm{H} 0: \gamma=0$ tests whether the model can be reduced to an SLM, and the hypothesis test of $H_{0}: \gamma+\delta \beta=0$ assesses whether the model can be reduced to an SEM.

\subsection{Indicator System}

\subsubsection{Index System Construction}

According to the above understanding of the basic concept, connotation, and theoretical basis of urban resilience, urban resilience refers to the degree to which an urban system can withstand and absorb the influence of various uncertain factors, as well as the ability to adapt, recover, and learn in response to disturbances. Regarding the construction of the evaluation index system of urban resilience level in Henan Province, the author has combed and collected urban resilience evaluation index systems at home and abroad (as shown in Table 1), taking into account the differences in urban development levels in Henan Province and the data available based on the degree of difficulty; the indicators are selected based on the principles of systematicity, scientificity, representativeness, and accessibility. This paper drawd on the urban resilience evaluation index system constructed by Yi Wu et al [51]. and Zheng Yan et al [52]. and established a total of 23 specific indicators to measure the level of urban resilience in Henan Province in four dimensions: economic resilience, social resilience, ecological resilience, and infrastructural resilience. From the perspective of economic resilience, economic resilience is mainly reflected in the stability and adaptability of the urban economic base and industrial structure when the system is disturbed by economic factors, including individuals, families, and enterprises [20]. In general, the higher the economic strength of a given city is, the more abundant the resources available for mobilization and the higher the ability to resist risks. To accurately reflect the vitality and strength of the urban economy, this paper adopts five economic indicators: the per capita GDP, public financial revenue, total utilized foreign capital, per capita disposable income of urban residents, and proportion of the output values of the secondary and tertiary industries in the GDP. From the perspective of social resilience, social resilience is largely reflected in the ability of an urban system to manage regional risks, which is closely related to social security services, social capital, and the individual development potential of a city [53]. Generally, a high level of social resilience can properly offset the external pressure exerted by the social environment and enhance the ability of a city to resist risks [54]. To better reflect and evaluate the social resilience of cities, seven social indicators are adopted in this paper: the urban registered unemployment rate, number of college students per 10,000 people, number of health workers per 10,000 people, proportion of the social security expenditure and employment in the fiscal expenditure, internet penetration rate, total postal and telecommunications services per capita, and medical insurance participation rate. From the perspective of ecological resilience, ecological resilience refers to the reorganization of the urban system to a stable state when the urban system responds to accidental and nonlinear risks, which focuses on the coordinated development of human and environmental systems [26]. The higher the degree of urban ecological resilience, the greater the ability of an ecosystem is to resist risks. To scientifically evaluate the ecological resilience of cities, seven ecological indicators are adopted in this paper: the green coverage in built-up areas, per capita green area, the comprehensive utilization rate of industrial solid waste, wastewater discharge per unit industrial output value, smoke and dust discharge per unit industrial output value, sewage treatment rate, and harmless disposal rate of domestic waste. From the perspective of infrastructural 
resilience, engineering resilience refers to the ability of infrastructures, such as water, roads, electricity, and networks, to support the development of modern cities to ensure minimal losses or reach another stable state when impacted by extreme events and disasters. As an important guarantee for the normal operation of the main urban body, engineering facilities can improve the technology and durability of the disaster-bearing body to a certain extent by strengthening the redundancy of engineering facilities. To accurately evaluate the urban engineering resilience, five engineering indicators are adopted in this paper: the urban drainage pipe density, number of buses owned per 10,000 people, urban per capita electricity consumption, and gas penetration rate. As shown in Table 2.

Table 1. Collection of relevant urban resilience evaluation index systems at home and abroad.

\begin{tabular}{|c|c|c|c|}
\hline $\begin{array}{l}\text { Research } \\
\text { Perspective }\end{array}$ & $\begin{array}{l}\text { First-Level Index } \\
\text { Selection }\end{array}$ & Selection of Secondary Indicators & Literature Source \\
\hline \multirow{3}{*}{$\begin{array}{l}\text { Evaluation of } \\
\text { Rural Social } \\
\text { Resilience }\end{array}$} & \multirow{3}{*}{$\begin{array}{l}\text { Economic resilience, } \\
\text { social resilience, and } \\
\text { ecological resilience }\end{array}$} & $\begin{array}{l}\text { Proportion of per capita income of farmers, yield of } \\
\text { economic crops, proportion of party members }\end{array}$ & \multirow{3}{*}{$\begin{array}{l}\text { Jianhong Fan et al. } \\
\text { (2021) [55] }\end{array}$} \\
\hline & & Proportion of migrant workers, proportion of cultural relics & \\
\hline & & $\begin{array}{l}\text { Area proportion of cultivated land, area proportion of forest } \\
\text { land, area proportion of ponds }\end{array}$ & \\
\hline
\end{tabular}

GDP per capita, per capita fiscal expenditure, the proportion of tertiary industry in GDP, per capita savings deposit balance, per capita investment in fixed assets, number of industrial enterprises above designated size

Number of college students per 10,000 people, number of hospital beds per 10,000 people, average salary of employees, proportion of employment in tertiary industry,

Evaluation of Urban Resilience in the Yellow River Basin
Economic resilience, social resilience, ecological resilience, and infrastructural resilience number of registered unemployed persons in urban areas, health technicians per 10,000 people

Park green area per capita, green coverage rate in built-up area, comprehensive utilization rate of industrial solid waste, harmless treatment rate of urban domestic garbage, industrial wastewater discharge per unit GDP, industrial smoke and dust emissions per unit of GDP

Road area per capita, number of buses per 10,000 people, density of urban drainage pipes, number of internet broadband users, electricity consumption per capita, number of mobile phone users at the end of the year
Dow Jones Sustainability World Index, GDP per square kilometer, per capita GDP, per capita investment in fixed assets, public budget expenditure, service output value ratio, urbanization rate, economic growth

Internet penetration rate, labor productivity in the construction industry, social resilience per capita disposable income RMB, per capita living space $(\mathrm{km}) 2$ / person, urban unemployment rate, Engel coefficient, higher education rate, number of doctors per ten thousand persons person, social dependency

Rate Energy waste ratio, energy density, energy renewable ratio, energy yield ratio, energy-based eco-efficiency indicator, environmental load ratio

Ratioroad mileage per capita, density of highway network, urban gas penetration rate, drainage density, safe drinking water coverage
Yi Wu et al. (2020) [51]
Yu Chen et al.

(2021) [56]
Evaluation of Ability
Economic resilience, ecological resilience, engingeering resilience 
Table 1. Cont.

\begin{tabular}{|c|c|c|c|}
\hline $\begin{array}{l}\text { Research } \\
\text { Perspective }\end{array}$ & $\begin{array}{l}\text { First-Level Index } \\
\text { Selection }\end{array}$ & Selection of Secondary Indicators & Literature Source \\
\hline \multirow{4}{*}{$\begin{array}{l}\text { About Beijing } \\
\text { Urban Resilience } \\
\text { Evaluation }\end{array}$} & \multirow{4}{*}{$\begin{array}{l}\text { Economic resilience, } \\
\text { social resilience, } \\
\text { ecological resilience, } \\
\text { and engineering } \\
\text { resilience }\end{array}$} & $\begin{array}{l}\text { Per capita GDP, government fiscal spending per capita, level } \\
\text { of urbanization, population density in built-up areas, } \\
\text { percentage of climate disaster economic loss in } \\
\text { GDP, urban per capita disposable income }\end{array}$ & \multirow{4}{*}{$\begin{array}{l}\text { Zheng Yan et al. } \\
\text { (2018) [52] }\end{array}$} \\
\hline & & $\begin{array}{l}\text { Ability for social development, percentage of population } \\
\text { receiving natural disaster relief fund, life expectancy, } \\
\text { insurance penetration and density, proportion of vulnerable } \\
\text { population }(<16 \text { or }>60 \text { years old), proportion of population } \\
\text { with minimum living standard, percentage of the } \\
\text { population with pension and property income, number of } \\
\text { resilient communities }\end{array}$ & \\
\hline & & $\begin{array}{l}\text { Ratio of environmental expenditure to fiscal expenditure, } \\
\text { percentage of afforested area, number of days with good air } \\
\text { quality }\end{array}$ & \\
\hline & & $\begin{array}{l}\text { Ability to manage urban risks, waterlogging points in urban } \\
\text { areas, traffic congestion index, public health facilities per } \\
\text { capita, broadcasting and television coverage }\end{array}$ & \\
\hline
\end{tabular}

Wetlands acreage and loss, erosion rates, impervious surface biodiversity, coastal defense structures

Demographics (age, race, class, gender, occupation, social networks and social embeddedness, community values-cohesion, faith-based organizations

Evaluation of community resilience based on natural disasters
Ecological, social, economic, institutional, infrastructure, and community competence

Economic employment, value of property wealth generation, municipal finance/revenues

Participation in hazard-reduction programs (NFIP, Storm Ready), hazard mitigation plans, emergency services, zoning and building standards, emergency response plans, interoperable communications, continuity of operations plans

Lifelines and critical infrastructure, transportation network, residential housing stock and age, commercial and manufacturing establishments

Local understanding of risk, counseling services, absence of psychopathologies (alcohol, drug spousal abuse), health and wellness (low rates mental illness, stress-related outcomes), quality of life (high satisfaction)

Electricity, water, sanitation, and solid waste disposal, accessibility of roads, housing, and land use

Population, health, education and awareness, social capital, community preparedness during a disaster

India Community

Resilience

Assessment
Physical, social, economic, institutional, and natural
Employment, finance and savings budget and subsidy, income, household assets

Mainstreaming of DRR and CCA, effectiveness of zone's crisis management framework, knowledge dissemination and management, institutional collaboration with other organizations and stakeholders, good governance

Ecosystem services, land use in natural term, environmental policies, intensity/severity of natural hazards, frequency of natural hazards
Cutter, S. L et al. (2008) [29]
Jonas Joerin et al.

(2012) [57] 
Table 2. Urban resilience index evaluation system and weight.

\begin{tabular}{|c|c|c|c|c|}
\hline Target Layer & Dimension Layer & Weight & Index Layer & Weight \\
\hline \multirow{23}{*}{$\begin{array}{c}\text { Urban resilience } \\
\text { level }\end{array}$} & \multirow{5}{*}{$\begin{array}{l}\text { Economic } \\
\text { resilience }\end{array}$} & \multirow{5}{*}{0.306} & Per capita GDP (yuan/person) [58] & 0.040 \\
\hline & & & Public financial revenue (100 million yuan) [55] & 0.132 \\
\hline & & & Total actual utilization of foreign investment (USD 10,000$)[59,60]$ & 0.087 \\
\hline & & & Per capita disposable income of urban residents (yuan) [55] & 0.034 \\
\hline & & & $\begin{array}{l}\text { Ratio of the output values of the secondary and tertiary industries } \\
\qquad \text { in the GDP }(\%)[56]\end{array}$ & 0.013 \\
\hline & \multirow{7}{*}{ Social resilience } & \multirow{7}{*}{0.425} & Urban registered unemployment rate (\%) [59] & 0.040 \\
\hline & & & Number of regular colleges and universities per 10,000 people [60] & 0.117 \\
\hline & & & Health personnel per 10,000 people (person) $[56,61]$ & 0.015 \\
\hline & & & $\begin{array}{c}\text { Social security expenditure and employment as a proportion of } \\
\text { the government expenditure }(\%)[58]\end{array}$ & 0.019 \\
\hline & & & Internet penetration rate $(\%)[62]$ & 0.040 \\
\hline & & & $\begin{array}{l}\text { Total postal and telecommunications services per capita } \\
\text { (RMB/person) [56] }\end{array}$ & 0.084 \\
\hline & & & Health insurance participation rate (\%) [52] & 0.111 \\
\hline & \multirow{7}{*}{$\begin{array}{l}\text { Ecological } \\
\text { resilience }\end{array}$} & \multirow{7}{*}{0.106} & Green coverage rate in built areas $(\%)[61]$ & 0.005 \\
\hline & & & Green area per capita $\left(\mathrm{m}^{2}\right)[63]$ & 0.056 \\
\hline & & & Comprehensive utilization rate of industrial solid waste (\%) [64] & 0.017 \\
\hline & & & $\begin{array}{l}\text { Wastewater discharge per unit of the industrial output value } \\
\text { (ton/ten thousand yuan) [64] }\end{array}$ & 0.006 \\
\hline & & & $\begin{array}{c}\text { Discharge of smoke and dust per unit of the industrial output } \\
\text { value (ton/ten thousand yuan) [64] }\end{array}$ & 0.008 \\
\hline & & & Sewage treatment rate $(\%)[62]$ & 0.007 \\
\hline & & & Harmless disposal rate of domestic waste (\%) [59] & 0.007 \\
\hline & \multirow{4}{*}{$\begin{array}{l}\text { Infrastructural } \\
\text { resilience }\end{array}$} & \multirow{4}{*}{0.163} & Density of urban drainage pipes $\left(\mathrm{m} / \mathrm{km}^{2}\right)[64]$ & 0.025 \\
\hline & & & Number of buses owned per 10,000 people [58] & 0.066 \\
\hline & & & Urban per capita electricity consumption $(\mathrm{kW} \cdot \mathrm{h} /$ person) [65] & 0.062 \\
\hline & & & Gas penetration rate $(\%)[58]$ & 0.010 \\
\hline
\end{tabular}

\subsubsection{Study Area}

Henan Province is located in the Central Plains region and has significant geographical advantages. It is an important comprehensive transportation hub and an information flow center for people and logistics in the country. It is rich in natural resources and is an important food province in China. This paper chooses Henan Province and its 18 prefecture-level cities as the research object. The typical characteristics of the selected research object are as follows: first, the urbanization rate in China reached 59.58\% in 2018, and the urbanization rate in Henan Province reached 53.21\%, ranking first in China in terms of urbanization rate growth. Second, in 2018, the total population of China reached 1.39538 billion people, and the total population of Henan amounted to 109.06 million people, ranking third in China in terms of permanent residents, thus making it the province with the largest population. Third, the GDP of Henan Province has remained at the forefront of China for a long time, but the per capita GDP ranks at the middle level in China, which is similar to the GDP status of China in the world. Fourth, the overall level of economic and social development in Henan Province is relatively high, but from a deeper level of research and analysis, Henan Province is still facing serious development crises in the process of urban development, such as environmental pollution, traffic congestion, low quality, and competition. Problems such as lack of strength, slow development speed, and unbalanced development have caused Henan Province to still have a relatively large gap with other economically developed provinces despite its remarkable achievements in economic development. Since the founding of New China 70 years ago, under the guidance of the national strategic thinking of "three-line construction" and "two overall situations", the rise of central China, the construction of "One Belt and One Road", the construction of urban agglomerations, and the construction of national central cities, Henan Province has 
been a key national guide and one of the important provinces cultivated as a representative province in the central region. Its spatial structure is unique, and it plays a decisive role in the spatial balance strategy implemented by the country. This article comprehensively evaluates the urban resilience level of Henan Province as a whole and the three major regions and prefectures from the perspective of spatial structure. It is of great strategic significance for enhancing the urban competitiveness of Henan Province, implementing the strategy for the rise of central China, and providing a reference for other inland cities.

According to the Central Plains Urban Agglomeration Development Plan, the 18 prefecture-level cities in Henan Province are divided into three major areas: the Zhengzhou metropolitan area, core development area, and linkage radiation area [66]. Among these areas, the Zhengzhou metropolitan area includes five prefecture-level cities, namely, Zhengzhou, Kaifeng, Xinxiang, Jiaozuo, and Xuchang. The core development area includes seven prefecture-level cities, namely, Luoyang, Pingdingshan, Hebi, Luohe, Shangqiu, Zhoukou, and the Jiyuan Demonstration Area (hereinafter referred to as Jiyuan). The linkage radiation area includes six prefecture-level cities, namely, Anyang, Puyang, Sanmenxia, Nanyang, Xinyang, and Zhumadian. The specific distribution is shown in Figure 1.

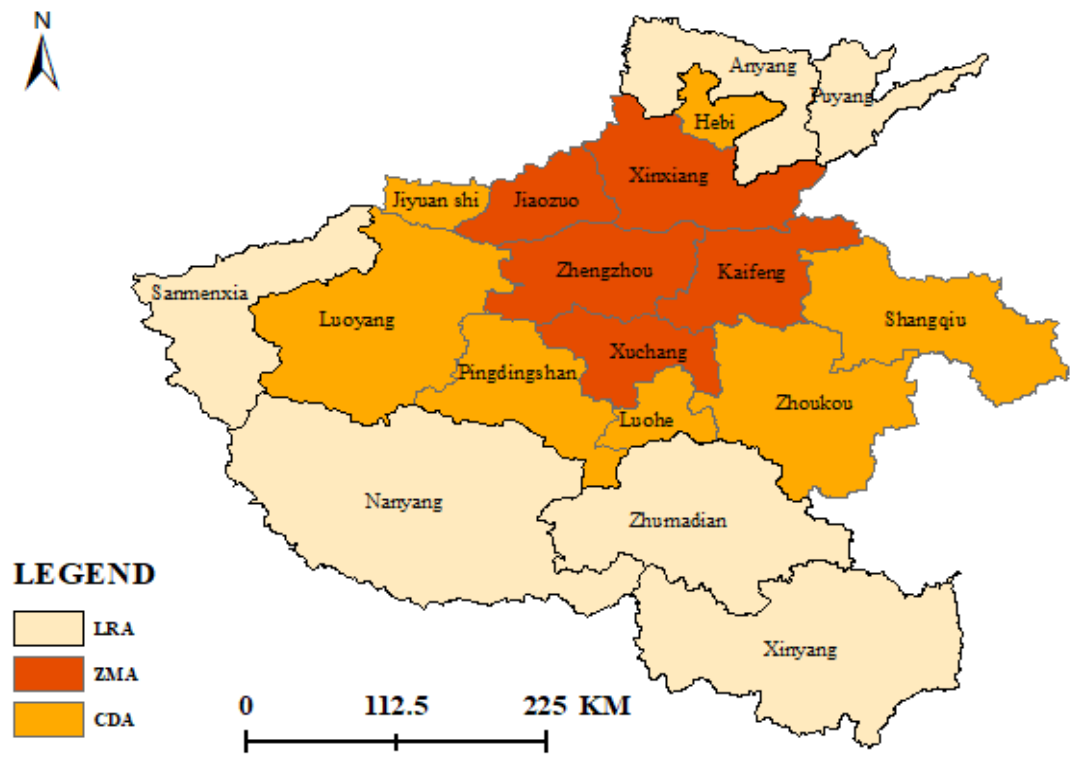

Figure 1. Division of the three major regions of the Zhengzhou metropolitan area, core development area, and linkage radiation area in Henan Province.

\subsubsection{Data Sources}

Considering the availability, authenticity, and integrity of the data, this paper selected 2009 to 2018 as the study period. The evaluation data originated from the Henan Statistical Yearbook (2009-2018), Statistical Yearbook of Chinese Cities (2009-2018), Statistical Yearbooks of Cities in Henan Province, Statistical Bulletin on the National Economic and Social Development of Each City, and Work Reports of the Municipal Governments. The relative economic data were debugged, and an interpolation method was adopted to supplement the original data due to the absence of individual data in certain years. To eliminate the difference in dimensions between the data, this paper adopted grade-difference standardization to achieve dimensionless processing of the original data.

\section{Results}

Based on the above research and analysis, this paper draws the following conclusions:

First, through the comprehensive measurement of urban resilience, it can be seen that in 10 years, the resilience of cities in Henan Province has shown an upward trend. Compared with the end of the period, the overall resilience level has increased in the initial year, but the absolute value was relatively small. In terms of the three major regions 
in Henan Province, the urban resilience level of the Zhengzhou metropolitan area was much higher than the average level of the province's core development areas and linkage radiation areas. The core development areas were consistent with the province's resilience development trend, and the linkage radiation areas were the lowest.

Secondly, the resilience of urban resilience subsystems in Henan Province shows a wave-like trend, and the overall resilience level and the resilience level of each subsystem have increased, and the growth rate was more obvious. Comparing the four major subsystems, the economic resilience level was the highest in the examined years, the trend was consistent with the overall resilience level, and the engineering resilience was the lowest. On the whole, social resilience has increased the most, while ecological resilience and engineering resilience have increased, but the overall magnitude was not large.

Third, according to the Thayer index and decomposition results, the degree of internal imbalance in the overall resilience of the whole city shows a curvilinear downward trend within the year of examination, with a significant reduction in the overall difference between the initial year and the end year, and the largest decrease in the Thayer index in 2017, with a 74\% decrease compared to 2016.

Fourth, from the perspective of spatial correlation analysis, the Moran Index indicated that the urban resilience level of Henan Province showed a significant positive spatial autocorrelation. The urban resilience spatial agglomeration characteristics of Henan Province are obvious, and the distribution of cold and hot spots is uneven. On the whole, the urban resilience $\mathrm{HH}$ clusters (high-efficiency type) in Henan Province were concentrated in Zhengzhou, Luoyang, and Jiaozuo (central Henan, western Henan), while the LL clusters (low-efficiency type) were distributed in Zhumadian and Xinyang (southern Henan), which was consistent with the first verification result. There were no HL aggregation (polarized) types and LH aggregation (hollow) state.

Fifth, in the evaluation of the influencing factors of urban resilience in Henan Province, because the urban resilience of Henan Province was affected by the explanatory variables and their lags, as well as some unobservable errors, the fixed-effect spatial Dubin model was selected for simulation. Among the six influencing factors of urban resilience selection in Henan Province, the local effects and spatial spillover effects of innovation, market power, and industrial structure on the overall resilience of the city were all positive; that is, these factors have a significant positive impact on the improvement of urban resilience in Henan Province. While the urbanization rate and administrative power had a positive impact on local resilience, they also showed a negative spillover response to the neighborhood. Only the openness failed the significance test and had a local effect on urban resilience. The spatial spillover effects of the neighborhood and the neighborhood were both negative.

\section{Discussion}

5.1. Temporal and Spatial Evolution Patterns of City Resilience in Henan Province

\subsubsection{Spatial and Temporal Evolution of Urban Resilience in Henan Province}

Based on the resilience development trend in the three major regional cities of Henan Province, the overall resilience level in the considered Henan Province cities is low, but a trend of sustained growth is observed. As shown in Figure 2, the overall urban resilience level in Henan Province rose from 0.104 in 2009 to 0.412 in 2018, an increase of 0.308 over 10 years, at an average annual growth rate of $29.6 \%$, indicating that the urban resilience in Henan Province exhibited an overall increase in characteristics since 2009. This occurred due to the Henan Provincial Government's emphasis on sustainable and healthy urban development over the past 10 years and the successive promulgation of policies aimed at the construction of high-quality cities, which created many dividends for urban resilience enhancement in Henan Province. However, the overall urban resilience in Henan Province from 2009 to 2018 reached a low level of 0.233, which remains far from the effective frontier, indicating that the urban resilience level in Henan Province should be improved. The urban resilience level in Henan Province in 2017 experienced a relatively large-scale increase, which was mainly attributed to the official issuance and implementation of the Central 
Plains City Cluster Development Plan in 2016 to encourage the advancement of the central region and promote the scientific development of the Central Plains City Cluster, which provided important strategic support, guaranteed urban resilience development in Henan Province, and effectively facilitated a notable increase in urban resilience. Moreover, this was inseparable from the improvement in the economic development level, the progress of science and technology, and the strengthening of the eco-environmental protection concept in recent years.

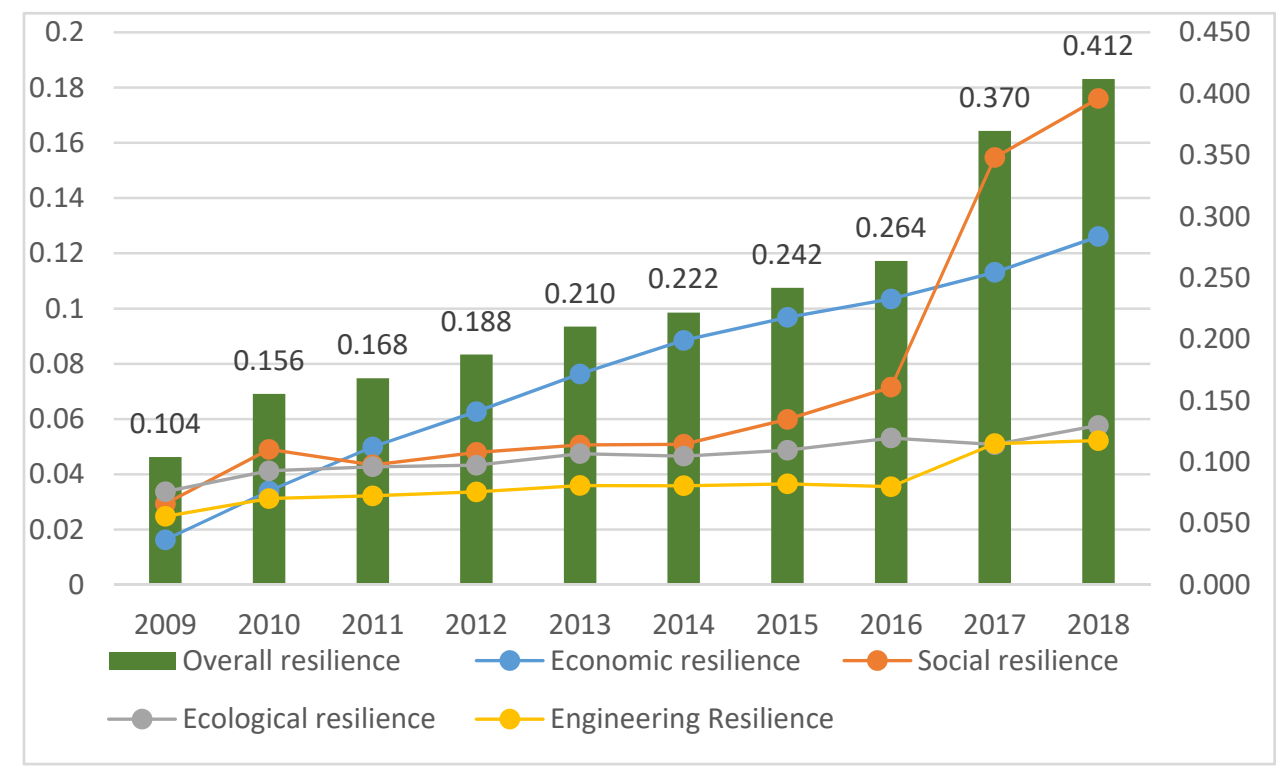

Figure 2. Overall urban and subsystem resilience levels in Henan Province from 2009 to 2018.

Table 3 indicates that, in general, the overall resilience level and the resilience level of each subsystem increased during the initial year and by the end of the period from 2009 to 2018, and growth was more obviously encountered, indicating that the overall situation of urban resilience development in Henan Province was suitable. Specifically, in regard to each subsystem, the economic resilience level $(0.0767)$ was the highest, followed by the social resilience level (0.0733). The economic and social resilience level indicated a steady growth trend and basically agreed with the overall urban resilience level in Henan Province. The levels were consistent, indicating that these two subsystems are the key factors promoting the overall resilience of Henan cities. In addition, the ecological resilience level $(0.0465)$ ranked third, and the engineering resilience level (0.0369) ranked at the bottom. The advancement of ecological and engineering resilience lagged, which has become a bottleneck in the development process of urban resilience in Henan Province. On the whole, although the ecological and engineering resilience levels increased, the overall extent was limited. This yielded a small contribution to the improvement in the urban resilience development level in Henan Province; much room for future improvement remains. 
Table 3. Overall urban resilience and subsystem resilience scores in Henan Province from 2009 to 2018 .

\begin{tabular}{cccccc}
\hline \multirow{2}{*}{ Year } & Overall Resilience & \multicolumn{3}{c}{ Subsystem Resilience } \\
\cline { 3 - 6 } & & $\begin{array}{c}\text { Economic } \\
\text { Resilience }\end{array}$ & $\begin{array}{c}\text { Social } \\
\text { Resilience }\end{array}$ & $\begin{array}{c}\text { Ecological } \\
\text { Resilience }\end{array}$ & $\begin{array}{c}\text { Engineering } \\
\text { Resilience }\end{array}$ \\
\hline 2009 & 0.1041 & 0.0163 & 0.0293 & 0.0337 & 0.0248 \\
2010 & 0.1555 & 0.0340 & 0.0490 & 0.0413 & 0.0312 \\
2011 & 0.1682 & 0.0499 & 0.0434 & 0.0427 & 0.0322 \\
2012 & 0.1875 & 0.0627 & 0.0479 & 0.0433 & 0.0336 \\
2013 & 0.2104 & 0.0763 & 0.0506 & 0.0475 & 0.0359 \\
2014 & 0.2218 & 0.0885 & 0.0509 & 0.0466 & 0.0358 \\
2015 & 0.2420 & 0.0968 & 0.0599 & 0.0487 & 0.0365 \\
2016 & 0.2637 & 0.1035 & 0.0715 & 0.0531 & 0.0355 \\
2017 & 0.3696 & 0.1131 & 0.1547 & 0.0508 & 0.0511 \\
2018 & 0.4120 & 0.1261 & 0.1760 & 0.0577 & 0.0522 \\
Mean & 0.2335 & 0.0767 & 0.0733 & 0.0465 & 0.0369 \\
\hline
\end{tabular}

\subsubsection{Spatial Evolution Pattern}

From the perspective of the overall development trend of the urban resilience level in Henan Province (as shown in Figure 2), the resilience levels of the cities in the three major regions exhibit notable differences, but they all indicate an upward development trend. From 2009 to 2017, the average urban resilience levels in the Zhengzhou metropolitan area, core development area, and linkage radiation area are 0.340,0.255, and 0.216, respectively, and the resilience level in the Zhengzhou metropolitan area is higher than the average level in the core development area, linkage radiation area, and province, and the lowest resilience level is observed in the linkage radiation area. This is closely related to the regional economic development level. The Zhengzhou metropolitan area is the core area of the Central Plains urban agglomeration and integrates economy, culture, industry, and population as the center. The urban infrastructure is complete, social resources are abundantly available, and the medical system and urban functions are comprehensive, so this area is resilient. The level is relatively high. From the perspective of the growth rate, the resilience level in the Zhengzhou metropolitan area rose from 0.218 in 2009 to 0.572 in 2018, an average annual growth rate of $16.2 \%$. The resilience level in the core development area increased from 0.169 in 2009 to 2018 0.441, an average annual increase rate of $16.1 \%$. The resilience level in the linkage radiation area increased from 0.134 in 2009 to 0.405 in 2018, an average annual increase rate of $20.2 \%$. At present, the growth rate of the resilience level in the linkage radiation area is higher than that in the Zhengzhou metropolitan area and core development area, reflecting that the linkage radiation area exhibits a good development momentum, but the overall resilience level in the region remains lower than the national average level. The main reason is that the economic foundation of the linkage radiation area is poor, and the urban development level is relatively lagging due to the influence of various factors, such as natural variables, human factors, and historical conditions.

To further analyze the spatial differences in urban resilience across Henan Province, the Theil index is adopted to decompose the urban resilience in Henan Province (as presented in Table 4). In general, the regional difference in urban resilience across Henan Province exhibits a development trend of increasing and then decreasing, from 0.0426 in 2009 to 0.0266 in 2018, a decrease of $60.15 \%$. Furthermore, core-edge spatial structure characteristics of the urban resilience in Henan Province are observed, but the overall difference is greatly reduced. From 2016 to 2017, the overall city-level Theil index dropped the most, by $74.5 \%$ below the 2016 level, mainly due to the implementation of the 2016 Central Plains Urban Agglomeration Development Plan, which provided a great opportunity to reduce regional differences in Henan Province. Strategic guidance and policy support could promote more coordinated and harmonious development of the Central Plains urban agglomeration. According to the decomposition results, the regional and interregional 
differences in urban resilience across Henan Province were similar to the overall differences, but the intraregional differences always exceeded the interregional differences. The average contribution rate of the intraregional differences from 2009 to 2018 reached $70.93 \%$. The contribution rate was much higher than that of the interregional differences $(29.06 \%)$. It could be concluded that the intraregional differences were the main cause of the regional differences in urban resilience across Henan Province.

Table 4. Decomposition of the Theil index of the urban resilience in Henan Province from 2009 to 2018.

\begin{tabular}{cccccc}
\hline Year & $\begin{array}{c}\text { Overall Regional } \\
\text { Differences }\end{array}$ & $\begin{array}{c}\text { Intraregional } \\
\text { Differences }\end{array}$ & $\begin{array}{c}\text { Contribution Rate of } \\
\text { the Intraregional } \\
\text { Differences (\%) }\end{array}$ & $\begin{array}{c}\text { Interregional } \\
\text { Differences }\end{array}$ & $\begin{array}{c}\text { Contribution Rate of } \\
\text { the Interregional } \\
\text { Differences (\%) }\end{array}$ \\
\hline 2009 & 0.0426 & 0.0303 & 71.10 & 0.0123 & 28.90 \\
2010 & 0.0384 & 0.0282 & 73.48 & 0.0102 & 26.52 \\
2011 & 0.0433 & 0.0311 & 71.84 & 0.0122 & 28.16 \\
2012 & 0.0450 & 0.0315 & 69.94 & 0.0135 & 30.06 \\
2013 & 0.0441 & 0.0314 & 71.10 & 0.0127 & 28.90 \\
2014 & 0.0460 & 0.0315 & 68.53 & 0.0145 & 31.47 \\
2015 & 0.0468 & 0.0309 & 66.17 & 0.0158 & 33.83 \\
2016 & 0.0466 & 0.0337 & 72.29 & 0.0129 & 27.71 \\
2017 & 0.0267 & 0.0195 & 72.80 & 0.0073 & 27.20 \\
2018 & 0.0266 & 0.0191 & 72.08 & 0.0074 & 27.92 \\
Mean & 0.0406 & 0.0287 & 70.93 & 0.0119 & 29.06 \\
\hline
\end{tabular}

\subsection{Spatial Correlation Analysis of the Urban Resilience in Henan Province}

To further explore the spatial agglomeration characteristics of urban resilience in Henan Province, GeoDa software was employed to determine the global Moran index (Moran scatter plot) and local Moran index (LISA cluster plot). The calculation results are provided in Table 5 and Figure 3.

Table 5. Moran's index of the urban resilience in Henan Province from 2009 to 2018.

\begin{tabular}{ccccccccccc}
\hline Year & $\mathbf{2 0 0 9}$ & $\mathbf{2 0 1 0}$ & $\mathbf{2 0 1 1}$ & $\mathbf{2 0 1 2}$ & $\mathbf{2 0 1 3}$ & $\mathbf{2 0 1 4}$ & $\mathbf{2 0 1 5}$ & $\mathbf{2 0 1 6}$ & $\mathbf{2 0 1 7}$ & $\mathbf{2 0 1 8}$ \\
\hline Moran's I & 0.155 & 0.168 & 0.137 & 0.127 & 0.113 & 0.094 & 0.087 & 0.060 & 0.068 & 0.066 \\
$z$-value (variance) & 2.364 & 2.387 & 2.263 & 2.204 & 2.107 & 2.115 & 2.133 & 1.835 & 1.839 & 1.847 \\
$p$-value & 0.01 & 0.02 & 0.04 & 0.04 & 0.04 & 0.05 & 0.05 & 0.05 & 0.05 & 0.05 \\
\hline
\end{tabular}

The results are listed in Table 5. The Moran index of the urban resilience level in Henan Province from 2009 to 2018 was positive, and all values passed the $95 \%$ significance level test, indicating that the urban resilience level in Henan Province attained a significantly positive spatial autocorrelation. The spatial distribution of the urban resilience level was not random but demonstrated a certain agglomeration effect. In particular, areas with high urban resilience levels were adjacent to other high-level areas, and areas with low urban resilience levels occurred adjacent to other low-level areas. Compared to 2009, the Moran index has decreased in recent years, reflecting differentiation in the spatial pattern of urban resilience development in Henan Province.

As shown in Figure 4, the Moran index of the urban resilience level in Henan Province in 2018 reached 0.066 , which indicates that there was a positive spatial correlation in the urban resilience development level among the 18 prefecture-level cities in Henan Province. To more intuitively reflect the urban resilience clustering degree in Henan Province in 2018, a dynamic distribution table was compiled based on the distribution of prefecture-level cities (Table 6). According to the Moran scatter diagram, the urban resilience level in Henan Province exhibits a significant dual spatial structure, namely, the Zhengzhou metropolitan area and core development area are mainly concentrated in the HH and HL quadrants. The radiation area largely occurs in the LL quadrant, and a positive spatial correlation is observed, but there is no clear spatial correlation between the cities. As the urban 
development planning system and space management system in Henan Province are not yet mature, there remains room for the coordinated development of the various regions, indicating that there is still a long way to go to promote coordinated urban resilience development in Henan Province in the present and in the future.

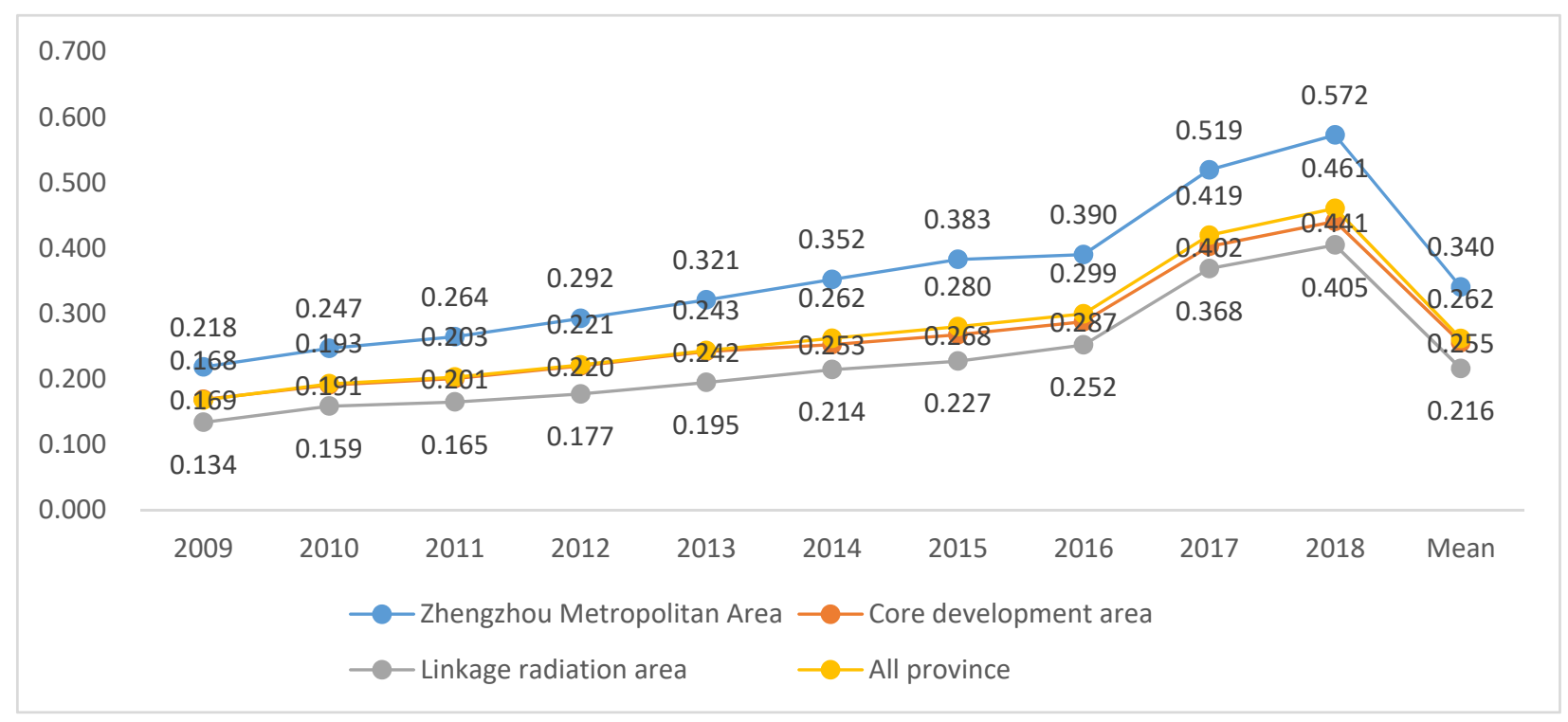

Figure 3. Development trend of the urban resilience level in Henan Province and the three major regions from 2009 to 2018.

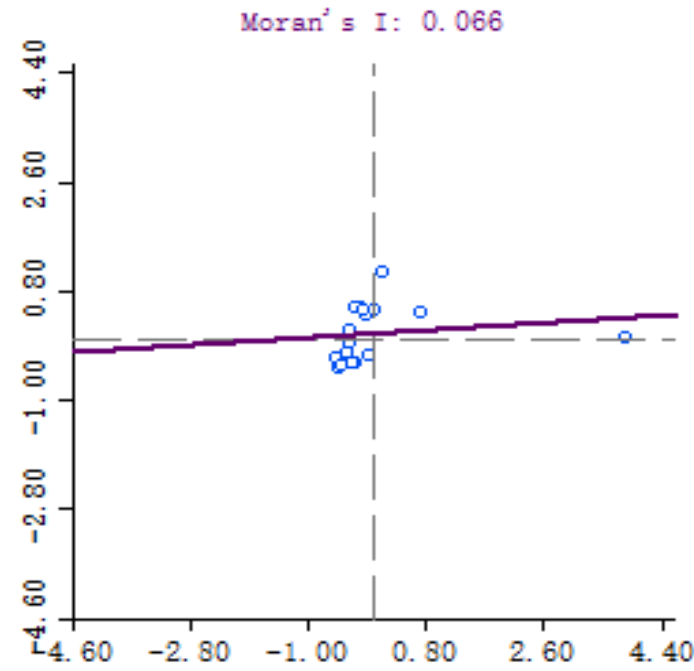

Figure 4. Moran scatter plot of the urban resilience level in Henan Province in 2018.

Table 6. The urban resilience level of Henan Province fell into the quadrant in 2018.

\begin{tabular}{cc}
\hline Fall into the Quadrant. & Area \\
\hline H-H & Luoyang, Zhengzhou, Jiaozuo, and Xinxiang \\
H-L & Sanmenxia, Pingdingshan, Jiyuan, Xuchang, and Kaifeng \\
L-L & Anyang, Shangqiu, Zhumadian, Nanyang, Hebi, Puyang, \\
L-H & Xinyang, and Zhoukou \\
None
\end{tabular}

The global Moran index can analyze the degree of spatial agglomeration of the urban resilience level in Henan Province as a whole and can better reveal the spatial characteristics of the urban resilience level in Henan Province, effectively distinguishing the degrees of 
local spatial agglomeration and dispersion and explore local spatial development models. The local Moran index is considered for measurement purposes. GeoDa software was adopted for calculation and to generate a LISA cluster map of the urban resilience level in Henan Province to reflect the autocorrelation degree between regions. In this study, we selected the four years of 2009, 2012, 2015, and 2018 to reveal the temporal and spatial evolution characteristics of the local spatial agglomeration of the urban resilience level in Henan Province. As shown in Figure 5, urban resilience level agglomeration in Henan Province from 2009 to 2017 mainly occurred as HH and LL agglomerations, among which Zhengzhou, Luoyang, and Jiao in the Zhengzhou metropolitan area were $\mathrm{HH}$ agglomerations, indicating that these cities possessed a better development foundation and long-term economic leadership, while the economic development level directly affected infrastructure and social development optimization and enhancement. Coupled with the implementation of policies such as urban ecological management and regional coordinated governance measures in recent years, the overall regional urban resilience was high. The LL agglomeration area was largely distributed in the linkage radiation area encompassing Zhumadian, Luohe, Xinyang, etc. These cities are located in the eastern and southern parts of Henan Province, mostly agricultural areas with a relatively low economic development level, poor social development conditions, and weak regional thematic functions. Coupled with the crude resource extraction method, the urban resilience level in the region was low. Therefore, the driving effect among the cities in the region occurring in the LL quadrant was not obvious. In addition, the number of cities in the low-high and high-low quadrants was zero, which indicates that the spatial heterogeneity in the urban resilience level in Henan Province was not notable.

\subsection{Analysis of the Influencing Factors of the Urban Resilience in Henan Province}

Through the above correlation test, it was found that no spatial correlation occurred in the urban resilience in Henan Province, and to further reveal the influencing factors of the urban resilience level in Henan Province, a spatial econometric model was applied in regression analysis in MATLAB 2019 software. Based on the principles of operability, science, and orientation of variable selection, six aspects highly relevant to urban resilience were selected as explanatory variables considering existing studies. (1) Urbanization rate (URB). Urbanization can create suitable objective conditions, such as a market, technology, and capital, and the urbanization level directly affects the degree of urban resilience development. The urbanization rate of the household population is adopted as a measure of the urbanization rate. (2) Administrative power (GOV). The degree of infrastructure improvement in cities is an important criterion of the urban resilience level. Moreover, urban infrastructure development cannot be achieved without the financial support of the government, and the general public expenditure is therefore chosen as a measure of the administrative power of the government. (3) Openness (OPE). The openness level of a city affects its industry, technology, employment, etc. Openness is an important factor in enhancing the vitality of the city. The amount of foreign capital used is selected to measure the openness level. (4) Innovation (INN). The urban innovation ability is the eternal driving force of the sustainable development of a city, and urban innovation is highly important to promote the transformation of the city from an industrial production base to an innovation base. The number of patent applications (pieces) is selected to measure the innovation ability. (5) Market power (MAR). The increase in marketization can stimulate the economic growth process of the city to a certain extent and enhance the city's vitality. The per capita retail sales of consumer goods are selected as a measure of marketization. (6) Industrial structure (IND). The adjustment of the industrial structure plays an important role in the transformation of the economy of a given city. The development of the tertiary industry is an important factor in the advancement of the industrial structure. The proportion of the output value of the tertiary industry in the total industrial output value is selected to measure the industrial structure. The data employed for the above variables are retrieved from the 2009-2018 Henan Provincial Statistical Yearbook and China City Statistical Yearbook. 


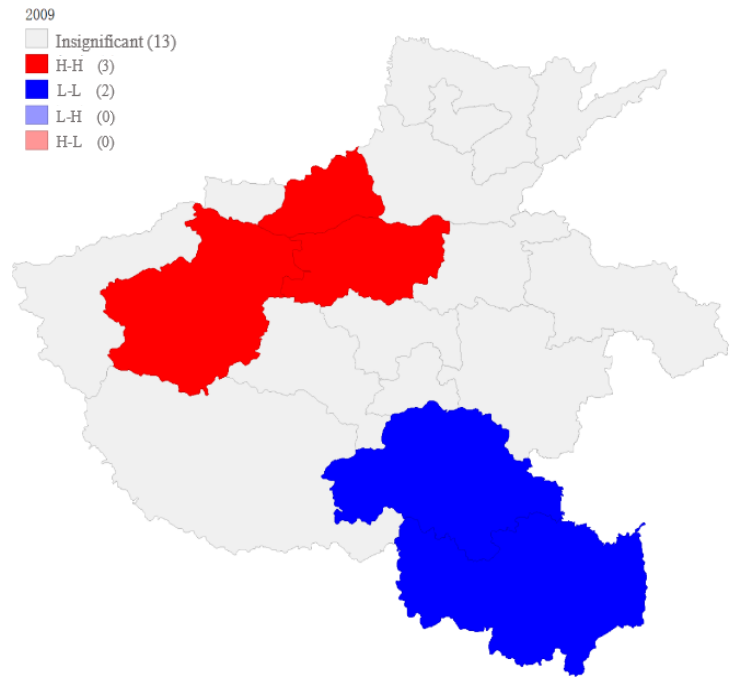

(a)

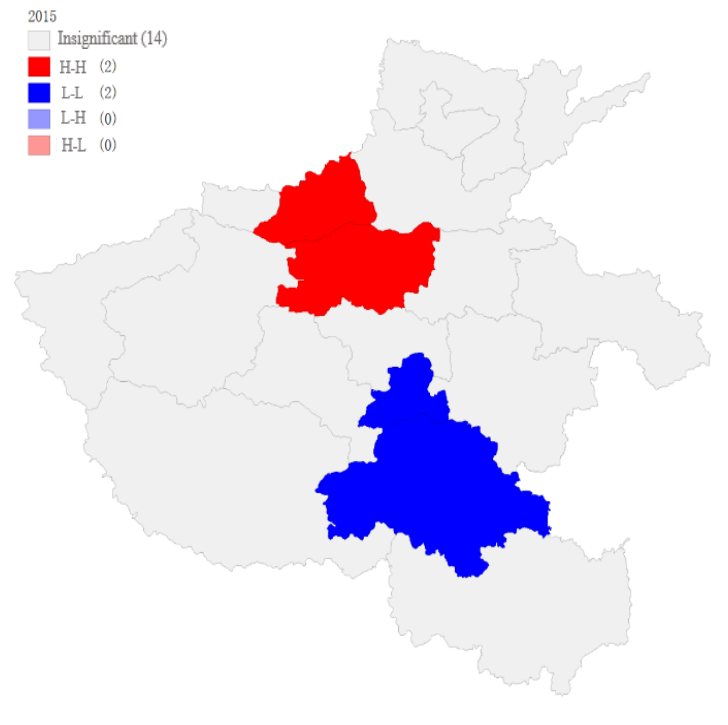

(c)

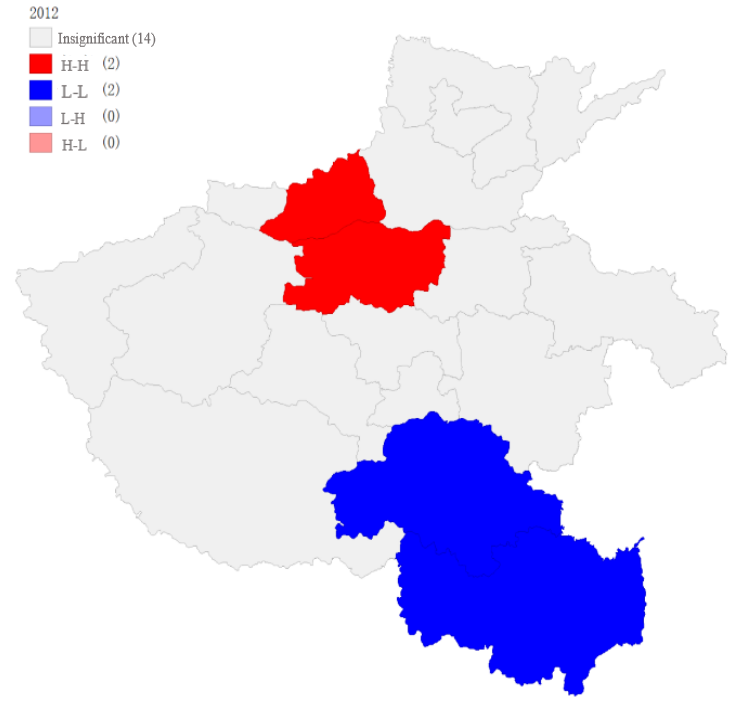

(b)

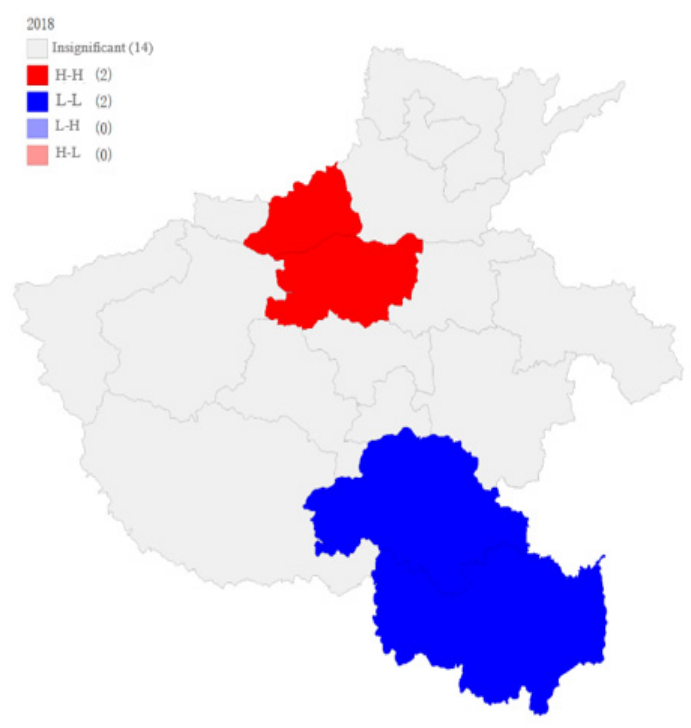

(d)

Figure 5. LISA cluster map of the urban resilience level in Henan Province, 2009-2018. (a) 2009; (b) 2012; (c) 2015 ; (d) 2018.

The formal test results for the model are listed in Table 7. The Hausman test demonstrates that the model passes the $1 \%$ significance level test, and the null hypothesis is thus rejected, indicating that the fixed-effects model is better than the random-effects model. Then, after the Wald and log-likelihood ratio (LR) tests, it is found that in both tests, the null hypothesis is rejected at the $10 \%$ significance level, which suggests that the SDM cannot be decomposed into an SLM (spatial autoregressive (SAR) model) nor an SEM. This further verifies that the urban resilience in Henan Province at the city scale is affected not only by the explanatory variables and their lags but also by certain unobservable error terms. Therefore, the SDM is chosen. Finally, according to the actual calculation results, comparative analysis of the three fixed-effects SDMs (spatial fixed-effects, temporal fixed-effects, and spatial and temporal dual fixed-effects models) reveals that the SDM with spatial and temporal dual fixed effects attains the highest R-squared value (0.9917) and the best goodness of fit. Hence, this paper selects the SDM with spatial and temporal dual fixed effects to obtain the final simulation results. 
Table 7. Estimation results of the spatial Durbin model.

\begin{tabular}{|c|c|c|c|c|c|c|}
\hline \multirow[t]{2}{*}{ Variable } & \multicolumn{2}{|c|}{ Spatial Effects } & \multicolumn{2}{|c|}{ Temporal Effects } & \multicolumn{2}{|c|}{$\begin{array}{l}\text { Spatial and Temporal Dual } \\
\text { Effects }\end{array}$} \\
\hline & Coefficient & $T$-Value & Coefficient & $T$-Value & Coefficient & $T$-Value \\
\hline URB & $0.631260^{* * *}$ & 2.800242 & $1.137301^{* * *}$ & 12.667972 & $0.550746^{* * *}$ & 2.898283 \\
\hline GOV & $0.24704^{* * *}$ & 3.892801 & $0.108825^{* * *}$ & 3.405156 & $0.184577^{* * *}$ & 3.279818 \\
\hline OPE & -0.008141 & 0.716516 & $-0.025937^{*}$ & -1.827564 & -0.004468 & -0.447238 \\
\hline INN & $0.022003 *$ & 1.915606 & $0.033219 * *$ & 2.063942 & $0.049402^{* * *}$ & 4.092026 \\
\hline MAR & $0.663102 * * *$ & 4.275594 & $0.466824^{* * *}$ & 9.363179 & $0.816606^{* * *}$ & 5.842973 \\
\hline IND & $-0.175079 * *$ & -2.229121 & 0.091639 & 1.371707 & $0.223963^{* * *}$ & 3.254567 \\
\hline $\mathrm{W} * \mathrm{URB}$ & & & & & -0.856805 * & -1.698346 \\
\hline $\mathrm{W} * \mathrm{GOV}$ & & & & & -0.354607 * & -2.546769 \\
\hline $\mathrm{W} * \mathrm{OPE}$ & & & & & -0.017814 & -0.549207 \\
\hline $\mathrm{W} * \mathrm{INN}$ & & & & & $0.109710^{* * *}$ & 3.870069 \\
\hline$W^{*}$ MAR & & & & & $1.093569 * * *$ & 3.188798 \\
\hline $\mathrm{W} * \mathrm{IND}$ & & & & & 0.154597 & 0.746214 \\
\hline$W *$ dep.var & $0.802987^{* * *}$ & 22.65956 & $0.342957^{* * *}$ & 5.164276 & 0.105996 & 1.119155 \\
\hline Hausman & \multicolumn{6}{|c|}{$28.2379 * * *$} \\
\hline R-squared & \multicolumn{2}{|c|}{0.9893} & \multicolumn{2}{|c|}{0.9643} & \multicolumn{2}{|c|}{0.9917} \\
\hline Log-likelihood & \multicolumn{2}{|c|}{269.32757} & \multicolumn{2}{|c|}{179.08951} & \multicolumn{2}{|c|}{314.29034} \\
\hline Wald test & \multicolumn{3}{|c|}{ Spatial lag $\left(21.7746^{* * *}\right)$} & \multicolumn{3}{|c|}{ Spatial error $\left(24.8093^{* * *}\right)$} \\
\hline LR test & \multicolumn{3}{|c|}{ Spatial lag $\left(20.5054^{* * *}\right)$} & \multicolumn{2}{|c|}{ Spatial error $\left(23.0478^{* * *}\right)$} & \\
\hline
\end{tabular}

Note: ${ }^{*}, * *$ and ${ }^{* * *}$ indicate significance levels of $10 \%, 5 \%$, and $1 \%$, respectively.

According to the estimation results in Table 6, (1) the local effect of the urbanization rate on urban resilience is positive and passes the $1 \%$ significance test. This indicates that an increase in the urbanization rate can promote regional economic development to a certain extent, improve the transformation and upgrading of industrial development, increase the industrial production efficiency, and provide a sustainable impetus for the development of resilient cities. However, the spatial spillover effect of this indicator is negative at the $10 \%$ significance level, which indicates that the siphoning effect of cities with a high urbanization rate could cause the migration of people, capital, technology, information, and other resources to cities with a high urbanization rate, and the development potential of neighboring cities could be reduced due to the outflow of resources, which hinders urban resilience improvement to a certain extent. (2) The administrative power variable passes the $1 \%$ significance level test. This indicates that government financial support is important in guiding resource factor allocation, infrastructure planning, and income redistribution within cities, which is conducive to managing the improvement in the urban resilience level in the right direction. However, this indicator also reveals a negative spillover effect, which suggests that local governments, in the process of urban resilience development promotion, focus excessively on the protection and development of cities within their region to the exclusion of outside cities, thereby ignoring synergistic regional development, which to a certain extent exerts downward pressure on the resilience of neighboring cities. (3) The local and spatial spillover effects of the openness level on urban resilience are both negative, and both fail the significance test. This indicates that Henan Province, which is located in the Central Plains, is a largely agricultural province with a low degree of openness to the outside world, and the effect of total real foreign capital utilization on urban resilience improvement in Henan Province has not yet been fully realized, but this does not suggest that the urban resilience improvement process in Henan Province does not require openness to the outside world but rather reflects that the response mechanism between urban resilience improvement in Henan Province and openness to the outside world should be further enhanced. (4) The local and spatial spillover effects of innovation on urban resilience are both positive, and both pass the $1 \%$ significance test. Urban resilience improvement is inseparable from the driving effect of innovation factors. The improvement of innovation capabilities can promote the optimization of the regional industrial structure, enhance the economic growth vitality of the city, retain technical 
talent, and yield a positive spillover effect on the surrounding areas. Therefore, in the process of advancing the construction of urban resilience, the improvement of innovation capabilities should be prioritized. (5) The local and spatial spillover effects of market forces on urban resilience are both positive at the $1 \%$ significance level, indicating that the development of marketization in Henan Province helps to improve the resilience level in local cities, and simultaneously, with the radiation and diffusion effects of the market, leads to the improvement of the resilience level cities in neighboring regions. (6) The local and spatial spillover effects of the industrial structure on urban resilience are positive, and the local effect is significantly positive at the $1 \%$ level. The adjustment and optimization of the industrial structure can boost the overall development of cities, especially in the traditionally agricultural Henan Province. The increase in the proportion of the tertiary industry basically agrees with the evolutionary pattern whereby the industrial structure tends to be highly developed, which is compatible with the current development level of the overall national economy.

In general, the urban resilience level of Henan Province has obvious characteristics of cluster distribution and unbalanced spatial distribution and gradually shows the characteristics of "core-periphery" in spatial changes. The reasons for this phenomenon are: first, the natural geographical conditions and population distribution of various regions in Henan Province are very different; second, since the founding of New China, especially after the reform and opening up, the regional coordinated development strategy has been implemented continuously, and the level of regional coordinated development in Henan Province has been improving, and great achievements have been made in coordinating urban and rural development, coordinating regional relations, optimizing spatial layout, and promoting regional cooperation. The third is that sub-regional cooperation continues to increase, and urban connections are becoming closer. In 2017, the construction of Zhengzhou, the capital city of Henan Province, was approved. During the rapid progress of the Zhengzhou metropolitan area, sub-regional cooperation, including Zheng Kai, Zheng Jiao, Zheng Xin, Zheng Xu, etc., has also accelerated, which has led to cooperation and the interconnection of regional transportation, economy, trade, culture, and education. Therefore, the concentration of production factors and industries makes the employment opportunities, public services, and education levels of Zhengzhou and surrounding areas in the east higher than other areas. As a result, although the southern and northern regions of Henan Province have good ecological advantages such as agriculture, land, and minerals, due to the high cost of resource output and lack of factor concentration, the industrial advantage of regional industrial clusters cannot be formed in the short term. There are also differences in economic, social, ecological, engineering (infrastructure), and other aspects between regions. This degree of unbalanced development is the main reason for the difference in elasticity index between regions. Therefore, in response to this phenomenon, this article focuses on the analysis of the influencing factors of the urban resilience level of Henan Province, from the six aspects of urbanization rate, administrative power, open power, innovation power, market power, and industrial structure. The analysis of the reasons for resilience results and the analysis of influencing factors explored in this article may provide references for other inland regions with comparable economic levels and geographic locations. Among China's 34 upgraded administrative regions, there are 12 inland provinces. As China's population and food province, Henan Province is actively promoting and exploring the construction of new urbanization. Assessing the regional resilience of Henan Province can not only guide the social development and planning of the region but also provide a wealth of practical cases for studying the regional resilience of developing countries.

\section{Conclusions and Recommendations}

\subsection{Conclusions}

Based on the panel data of 18 cities in the YRB from 2009 to 2018, the temporal and spatial differentiation characteristics of urban resilience in Henan Province were analyzed, 
and a spatial measurement model was used to analyze the influencing factors of urban resilience. The main conclusions are as follows: (1) the overall resilience in Henan Province exhibits an evolutionary trend from a low level to a high level, but there are differences in the growth rate and trend. The three major urban regions in Henan Province from 2009 to 2017 are ranked as the Zhengzhou metropolitan area, core development area, and linkage radiation area. (2) The urban subsystem resilience in Henan Province reveals a growing trend, and the order of the resilience of the four subsystems is economic resilience, social resilience, ecological resilience, and engineering resilience. The overall resilience is mainly driven by economic and social resilience. (3) In terms of the global spatial characteristics, the Henan Province region exhibits a positive spatial correlation, and the urban resilience level in Henan Province exhibits significant dual structural characteristics of the spatial structure. (4) Among the influencing factors of the indicators of the urban resilience in Henan Province, the overall local effects of the urbanization rate, administrative power, innovation ability, market forces, and industrial structure factors are positive, and the local effect of the openness level on the urban resilience is negative. The spatial spillover characteristics of each influencing factor on the urban resilience in Henan Province are significantly differentiated.

The shortcomings of the paper are: (1) the exploration of urban resilience in this paper is at the preliminary stage. Since the academic community has not yet reached a consensus on the basic connotation and evaluation criteria of urban resilience, future urban resilience research will start more from the basic concept of urban resilience and explore the scientific connotation and framework structure of urban resilience from a diversified and composite perspective. (2) As the urban system and its resilience components are complex and diverse, in addition to the contradiction between internal and external factors, there are many other factors that affect system resilience, and each specific study is only discussed from a certain aspect. The discussion in this article covers urban resilience from the four dimensions of economy, ecology, society, and engineering and is more inclined to the discussion of the macro-city system. However, in the selection of secondary indicators, due to the limitation of data, the selection of indicators is mostly based on the data publicly announced by the state. In addition, the community, policy system [67], cultural aspects [68], human quality, and creativity are also important components of urban resilience, but these indicators are not included in the indicator system due to the difficulty of obtaining data. In the future, further research will be focused on the perfection of the indicator system. (3) The research unit of this paper is the county and urban area, and the granularity of the unit is large, so the precision of the research needs to be further improved, and the resilience level of cities can be explored at the community and township levels in the future.

\subsection{Policy Suggestions}

Based on the above research results, this paper proposes the following policy recommendations: (1) the development of new urbanization should be continuously promoted. Henan Province, as a highly populated and agricultural and new industrial province, exhibits a large gap between its urbanization level and the national level. Therefore, with policy adjustment and environmental improvement, Henan Province should follow the law of urban development, continuously enhance urban planning and spatial design, coordinate urban and rural construction, focus on the mitigation of infrastructure shortcomings, integrate urban-rural development, comprehensively improve public, municipal and educational facilities, and promote new urbanization toward scientific and rationalization. (2) Coordinated development of the region should be strengthened. We should fully manifest the policy role of the regional coordinated development strategy, deepen the integrated development of the Central Plains city cluster, promote the construction of Zhengzhou as a national central city, support the construction of Luoyang as a subcenter city, and establish a model in which the Zhengzhou metropolitan area leads the development of central cities, central cities spearhead the development of city clusters, and city clusters drive coordinated regional development. Moreover, it is necessary to 
strengthen the exchange and communication between economic, scientific and educational, ecological and other systems; optimize the spatial allocation structure of resources; form a collaborative and cooperative environment at all levels; create favorable conditions for the reasonable flow of various factors and resources; enhance the spatial spillover effects between neighboring regions; and realize integrated regional development. (3) The role of government financial support should be fully manifested. Financial system reform should be deepened, diversification of economic industries should be enhanced, the financial expenditure policy of each city in Henan Province should be adjusted, the positive role of government financial support should be fully facilitated in terms of the resilience of local urban projects, and full protection of urban infrastructure investment should be realized, while any administrative barriers to the flow of production factors should be overcome, economic exchange and cooperation between local cities should be facilitated, and the problems of duplication and vicious competition should be avoided in infrastructure construction between cities. Based on unified and rational planning, the benefits of interregional infrastructure investment and construction services should be maximized. (4) A new highland should be created for the two-way opening of inland areas. Internally, it is necessary to increase market activity, focus on the enhancement of housing, social security, and social services, release the comprehensive purchasing power of the people, and further actively develop online consumption, promote the diversified development of consumption patterns, and stimulate the innovation vitality of the market simultaneously. Externally, Henan Province is an inland province in the Central Plains. Compared to the national average, the openness level of Henan Province to the outside world still exhibits much room for improvement. Therefore, Henan Province should implement a more proactive opening strategy, vigorously develop an inland open economy, strengthen the opening door function of Zhengzhou Airport and other important transportation hubs, promote the construction of the Henan Free Trade Pilot Zone, accelerate the construction of Zhengzhou as a service outsourcing demonstration city, introduce well-known Chinese and foreign enterprises, undertake the transfer of the international service industry, create a comprehensive, multilevel, and wide-ranging two-way open pattern, and accelerate the formation of an inland open cooperation demonstration zone with global influence. (5) The scientific and educational innovation environment should be enhanced, and the innovation ability of the social system should be improved. With structural adjustment, transformation, and upgrading of economic development, innovation could become an important driving force of urban development. Since the improvement in the social system's innovation ability cannot be separated from the support of government policies, to improve the innovation ability in Henan Province, we should first strengthen the guidance effect of government policies, adhere to the core position of scientific and technological innovation in overall modernization construction, implement the concept of innovation and development, and focus on attracting and cultivating innovative industries. In addition, it is necessary to vigorously develop education. On the one hand, the quality and level of education in Henan Province should be comprehensively improved, and on the other hand, balanced development of education should be promoted. In eastern, western, and southern Henan, where educational resources are relatively scarce, the availability of educational resources should be enhanced. (6) The industrial structure should be adjusted, and optimization and upgrading of the industrial structure should be encouraged. It is necessary to comprehensively consider the market characteristics of the various regions in Henan Province, fully utilize the industrial structure of Henan Province to build an important national food production base, energy raw material base, modern equipment manufacturing and high-tech industrial bases, and comprehensive transportation hub policy support conditions. Based on the objective development of laws, an industrial structure with a reasonable layout and complementary advantages between neighboring regions should be established to form industrial clusters. First, the industrial structure should be scientifically adjusted. The traditional economic model relying on the development of agriculture and heavy industry should be modified, and the new industrial development model led by the tertiary industry 
should be adjusted and transformed in a timely manner. Second, we should focus on the cultivation of new industries, dynamics and growth poles, and the digital economy, information technology, biomedicine, high-end equipment manufacturing, new energy, new materials, and other strategic emerging industries should be assigned the top priority.

Author Contributions: Conceptualization, L.L., Y.L. (Yun Luo), and J.P.; methodology, L.L. and J.P.; validation, L.L., J.L. and H.W.; data curation, L.L., H.W. and Y.L. (Ying Li); writing-review and editing, L.L. and Y.L. (Yun Luo). All authors have read and agreed to the published version of the manuscript.

Funding: This research was funded by the National Natural Science Foundation of China: "Risk Assessment of Urban Accidents and Disasters and Research on the Theory and Method of Resilience Air Defense" (52004258).

Institutional Review Board Statement: Not applicable.

Informed Consent Statement: Not applicable.

Data Availability Statement: The evaluation data selected in this article are all derived from the "Henan Provincial Statistical Yearbook" (2009-2018), "China City Statistical Yearbook" (2009-2018), the statistical yearbook of each city in Henan Province, the statistical bulletin of the national economy and social development of each city, and the work of the municipal government Report etc.

Conflicts of Interest: The authors declare no conflict of interest.

\section{References}

1. China Jiangsu Net. The United Nations Predicts That the Urban Population Will Reach $66 \%$ of the World's Total Population by 2050. Available online: https:/ / baijiahao.baidu.com/s?id=1596073338476670672\&wfr=spider\&for=pcInternational (accessed on 10 September 2020).

2. Brecht, H.; Deichmann, U.; Wang, G.H. A Global Urban Risk Index. In R. Policy Research Working Paper; The World Bank Publication: Washington, DC, USA, 2013.

3. China Insurance News. Lloyd's City Risk Index Report 2018: Which Chinese Cities Face High Risks? [EB/OL]. Available online: https:/ / www.sohu.com/a/235372948_618588 (accessed on 17 November 2020).

4. Holling, C.S. Resilience and Stability of Ecological Systems. Annu. Rev. Ecol. Syst. 1973, 4, 1-23. [CrossRef]

5. Berkes, F.; Folke, C. (Eds.) Linking social and ecological systems for resilience and sustainability. In Linking Social and Ecological Systems: Management Practices and Social Mechanisms for Building Resilience; Cambridge University Press: Cambridge, UK, 1998; pp. 13-20.

6. Carpenter, S.; Walker, B.; Anderies, J.M.; Abel, N. From metaphor to measurement: Resilience of what to what? Ecosystems 2001, 4, 765-781. [CrossRef]

7. Folke, C. Resilience: The emergence of a perspective for social-ecological systems analyses. Global Environ. Chang. 2006, 16, 253-267. [CrossRef]

8. Motesharrei, S.; Rivas, J.; Kalnay, E.; Asrar, G.R.; Busalacchi, A.J.; Cahalan, R.F.; Cane, M.A.; Colwell, R.R.; Feng, K.; Franklin, R.S.; et al. Modeling sustainability: Population, inequality, consumption, and bidirectional coupling of the Earth and Human Systems. Natl. Sci. Rev. 2016, 3, 470-494. [CrossRef] [PubMed]

9. Spaans, M.; Waterhout, B. Building up resilience in cities worldwide-Rotterdam as participant in the 100 Resilient Cities Programme. Cities 2017, 61, 109-116. [CrossRef]

10. Nan, S. Introduction to habitat III and new city agenda, and their inspiration to China. City Plann. Rev. 2017, 41, 9-21.

11. The World Bank. World Development Report 2009; The World Bank: Washington, DC, USA, 2008; pp. 73-78.

12. Jha, A.K.; Miner, T.W.; Stanton-Geddes, Z. Building Urban. Resilience: Principles, Tools, and Practice; World Bank Publications: Washington, DC, USA, 2013.

13. Godschalk, D.R. Urban hazard mitigation: Creating resilient cities. Nat. Hazards Rev. 2003, 4, 136-143. [CrossRef]

14. Bozza, A.; Asprone, D.; Manfredi, G. Developing an integrated framework to quantify resilience of urban systems against disasters. Nat. Hazards. 2015, 78, 1729-1748. [CrossRef]

15. Chi, S.; Tianxin, H. Resilient City: A New Concept for Resolving Urban Disasters. City Disaster Reduct. 2017, 4, 1-4. (In Chinese)

16. Meerow, S.; Newell, J.P.; Stults, M. Defining urban resilience: A review. Landsc. Urban. Plan. 2016, 147, 38-49. [CrossRef]

17. Yiwen, S.; Jiang, X. Urban resilience: A conceptual analysis based on international literature review. Int. Urban. Plan. 2015, 30, 48-54. (In Chinese)

18. Habitat, U.N. An Urbanizing World: Global Report on Human Settlements; Oxford University Press: Oxford, UK, 1996.

19. Resilience Alliance. Urban. Resilience Research Prospectus; CSIRO: Canberra, Australia, 2007; pp. $20-21$.

20. Tompkins, J.A. Four steps to business resilience. Ind. Manag. 2007, 4, 14-18, 49.

21. Hang, S. Research Progress on Economic Resilience. J. Econ. 2015, 8, 144-151. (In Chinese) 
22. Holling, C.S.; Gunderson, L.H. Barriers and Bridges to the Renewal of Ecosystems and Institutions; Columbia University Press: New York, NY, USA, 1995; pp. 20-41.

23. Yan, Z.; Wenjun, W.; Jiahua, P. Low-carbon Resilient Cities: Concepts, Approaches and Policy Options. Urban. Dev. Res. 2013, 20, 10-14. (In Chinese)

24. Sun, Y.N.; You, X.T. Measurement of Urban Resilience Level and Its Spatio-temporal Evolution Law: Taking Jiangsu Province as an Example. Nanjing Soc. Sci. 2021, 7, 31-40, 48. (In Chinese)

25. Ya, L.; Guofang, Z.; Fumei, G. Summary of Research on Quantitative Evaluation Methods of Urban Infrastructure Resilience. Urban. Dev. Res. 2016, 23, 113-122. (In Chinese)

26. Adger, W.N. Social and ecological resilience: Are they related? Prog. Hum. Geogr. 2000, 24, 347-364. [CrossRef]

27. Xuecheng, M.; Jie, G.; Dongqing, L.; Jinxi, Z. Review of social-ecological system research: An analysis based on bibliometrics. Adv. Earth Sci. 2018, 33, 435-444. (In Chinese)

28. Romero-Lankao, P.; Gnatz, D.M.; Wilhelmi, O.; Hayden, M. Urban Sustainability and Resilience: From Theory to Practice. Sustainability 2016, 8, 1224. [CrossRef]

29. Cutter, S.L.; Barnes, L.; Berry, M.; Burton, C.; Evans, E.; Tate, E.; Webb, J. A place-based model for understanding community resilience to natural disasters. Glob. Environ. Chang. 2008, 18, 598-606. [CrossRef]

30. Sharifi, A.; Roosta, M.; Javadpoor, M. Urban Form Resilience: A Comparative Analysis of Traditional, Semi-Planned, and Planned Neighborhoods in Shiraz, Iran. Urban. Sci. 2021, 5, 18. [CrossRef]

31. Jabareen, Y. Planning the resilient city: Concepts and strategies for coping with climate change and environmental risk. Cities 2013, 31, 220-229. [CrossRef]

32. The Rockefeller Foundation. 100 Resilient Cities. Available online: https://www.rockefellerfoundation.org/our-work/initiatives / 100-resilient-cities (accessed on 10 September 2021).

33. Brunetta, G.; Faggian, A.; Caldarice, O. Bridging the Gap: The Measure of Urban Resilience. Sustainability 2021, 13, 1113. [CrossRef]

34. Manika, S.; Karalidis, K.; Gospodini, A. Mechanism for the Optimal Location of a Business as a Lever for the Development of the Economic Strength and Resilience of a City. Urban. Sci. 2021, 5, 70. [CrossRef]

35. Nyström, M.; Jouffray, J.B.; Norström, A.V.; Crona, B.; Jørgensen, P.S.; Carpenter, S.R.; Bodin, Ö.; Galaz, V.; Folke, C. Anatomy and resilience of the global production ecosystem. Nature 2019, 575, 98-108. [CrossRef] [PubMed]

36. O'Connell, D.; Walker, B.; Abel, N.; Grigg, N. The resilience, adaptation, and transformation assessment framework: From theory to application. J. Canberra Csiro 2015, 2015. [CrossRef]

37. Yang, S.; Luocheng, Z.; Shimou, Y. Evaluation of resilience of prefecture-level cities in the Yangtze River Delta from the perspective of the social ecosystem. China Popul. Resour. Environ. 2017, 27, 151-158. (In Chinese)

38. Zhang, M.D.; Feng, X.Q. Comprehensive evaluation of urban resilience in China. Urban. Issues 2018, 10, 27-36.

39. Song, J.; Huang, B.; Li, R. Assessing local resilience to typhoon disasters: A case study in Nansha, Guangzhou. PLoS ONE 2018, 13, e0190701. (In Chinese) [CrossRef]

40. Suárez, M.; Gómez-Baggethun, E.; Benayas, J.; Tilbury, D. Towards an urban resilience Index: A case study in 50 Spanish cities. Sustainability 2016, 8, 774. [CrossRef]

41. Heeks, R.; Ospina, A.V. Conceptualising the link between information systems and resilience: A developing country field study. Inf. Syst. J. 2019, 29, 70-96. [CrossRef]

42. Tongyue, L. New progress in the research of resilient cities. J. Int. Urban. Plan. 2017, 32, 15-25. (In Chinese)

43. Parsons, M.; Morley, P. The Australian natural disaster resilience index. Aust. J. Emerg. Manag. 2017, $32,20$.

44. Changkun, C.; Yiqin, C.; Bo, S.; Tong, X. Urban resilience assessment model in the context of rain and flood disaster. Chin. Saf. Sci. J. 2018, 28, 1-6. (In Chinese)

45. Bruneau, M.; Chang, S.E.; Eguchi, R.T.; Lee, G.C.; O’Rourke, T.D.; Reinhorn, A.M.; Shinozuka, M.; Tierney, K.; Wallace, W.A.; von Winterfeldt, D. A framework to quantitatively assess and enhance the seismic resilience of communities. Earthq. Spectra. 2003, 19, 733-752. [CrossRef]

46. Ye, T.; Jin, H.; Min, A. Evaluation of the efficiency of agricultural modernization development under the strategy of rural revitalization-Based on the combined analysis of super-efficiency DEA and comprehensive entropy method. Issues Agric. Econ. 2021, 3, 100-113. (In Chinese)

47. Theil, H. Economics and Information Theory; North-Holland: Amsterdam, The Netherlands, 1967.

48. Zhou, L.Q.; Cheng, Y.Q. Spatial-temporal pattern and motivation analysis of grain production in Heilongjiang Province. J. Nat. Resour. 2015, 30, 491-501. (In Chinese)

49. Anselin, L. Local indicators of spatial association-LISA. Geogr. Anal. 1995, 27, 93-115. [CrossRef]

50. Anselin, L.; Griffith, D.A. Do spatial effects really matter in regression analysis? Pap. Reg. Sci. 1988, 65, 11-34. [CrossRef]

51. Wu, Y.; Que, W.; Liu, Y.G.; Cao, L.; Liu, S.B.; Zhang, J. Is resilience capacity index of Chinese region performing well? Evidence from 26 provinces. Ecol. Indic. 2020, 112, 106088. [CrossRef]

52. Zheng, Y.; Xin-Lu, X.; Chen-Zhen, L.; Mou, W.; Xiao-Jia, H.E. Development as adaptation: Framing and measuring urban resilience in Beijing. Adv. Clim. Chang. Res. 2018, 9, 234-242. [CrossRef]

53. Du, Z.; Zhang, H.; Ye, Y.; Jin, L.; Xu, Q. Urban shrinkage and growth: Measurement and determinants of economic resilience in the Pearl River Delta. J. Geogr. Sci. 2019, 29, 1331-1345. [CrossRef] 
54. Liu, Y.P. Measurement of Urban Resilience System Development-Based on an Empirical Study of 288 Cities in China. Urban. Dev. Res. 2021, 6, 93-100. (In Chinese)

55. Fan, J.; Mo, Y.; Cai, Y.; Zhao, Y.; Su, D. Evaluation of Community Resilience in Rural China-Taking Licheng Subdistrict, Guangzhou as an Example. Int. J. Environ. Res. Public Health 2021, 18, 5827. [CrossRef] [PubMed]

56. Chen, Y.; Su, X.; Zhou, Q. Study on the Spatiotemporal Evolution and Influencing Factors of Urban Resilience in the Yellow River Basin. Int. J. Environ. Res. Public Health 2021, 18, 10231. [CrossRef] [PubMed]

57. Joerin, J.; Shaw, R.; Takeuchi, Y.; Krishnamurthy, R. Action-oriented resilience assessment of communities in Chennai, India. Environ. Hazards 2012, 11, 226-241. [CrossRef]

58. Limin, B.; Chunliang, X.; Xinghua, F.; Dawei, M.; Ye, W. Comprehensive assessment of urban resilience in China and its spatial and temporal differentiation characteristics. World Reg. Stud. 2019, 28, 77-87. (In Chinese)

59. Jinhe, Z.; Hongxue, S. Study on the spatio-temporal evolution and influencing factors of urban resilience in three major urban agglomerations in China. Soft Sci. 2020, 34, 72-79. (In Chinese)

60. Alexeeff, G.V.; Faust, J.B.; August, L.M.; Milanes, C.; Randles, K.; Zeise, L.; Denton, J. A screening method for assessing cumulative impacts. Int. J. Environ. Res. Public Health 2012, 9, 648-659. [CrossRef] [PubMed]

61. Zhang, P.; Yu, W.; Zhang, Y.W. Spatial and temporal divergence of urban resilience in Shandong Province and its influencing factors. Urban Probl. 2018, 9, 27-34. (In Chinese)

62. Yang, S.; Chengcheng, Z.; Shimou, Y. Evaluation of the resilience of Yangtze River Delta prefecture-level cities based on social-ecological system perspective. China Popul. Resour. Environ. 2017, 27, 151-158. (In Chinese)

63. Kammouh, O.; Zamani Noori, A.; Cimellaro, G.P.; Mahin, S.A. Resilience assessment of urban communities. Asce-Asme J. Risk Uncertain. Eng. Syst. Part A Civ. Eng. 2019, 5, 04019002. [CrossRef]

64. Chen, Y.; Zhu, M.; Zhou, Q.; Qiao, Y. Research on spatiotemporal differentiation and influence mechanism of urban resilience in China based on MGWR model. Int. J. Environ. Res. Public Health 2021, 18, 1056. [CrossRef] [PubMed]

65. Zhaofeng, X.; Jiefang, T.; Jing, Z. Urban resilience evaluation system and optimization strategy from disaster prevention perspective. China Saf. Sci. J. 2019, 29, 1-7. (In Chinese)

66. The Development and Reform Commission of the People's Republic of China. The Notice of the National Development and Reform Commission on Printing and Distributing the Central Plains Urban Agglomeration Development Plan. Available online: http:/ / www.gov.cn/xinwen/2017-01/05/content_5156816.htm (accessed on 10 September 2021).

67. Shahab, S.; Hartmann, T.; Jonkman, A. Strategies of municipal land policies: Housing development in Germany, Belgium, and Netherlands. Eur. Plan. Stud. 2021, 29, 1132-1150. [CrossRef]

68. Hartmann, T.; Jehling, M. From diversity to justice-Unraveling pluralistic rationalities in urban design. Cities 2019, 91, 58-63. [CrossRef] 